$12-2019$

\title{
PALEOSEISMOLOGY OF THE CENTRAL GARLOCK FAULT IN SEARLES VALLEY, CALIFORNIA
}

Kyle Pena

Follow this and additional works at: https://scholarworks.lib.csusb.edu/etd

Part of the Geology Commons, and the Tectonics and Structure Commons

\section{Recommended Citation}

Pena, Kyle, "PALEOSEISMOLOGY OF THE CENTRAL GARLOCK FAULT IN SEARLES VALLEY, CALIFORNIA" (2019). Electronic Theses, Projects, and Dissertations. 956.

https://scholarworks.lib.csusb.edu/etd/956

This Thesis is brought to you for free and open access by the Office of Graduate Studies at CSUSB ScholarWorks. It has been accepted for inclusion in Electronic Theses, Projects, and Dissertations by an authorized administrator of CSUSB ScholarWorks. For more information, please contact scholarworks@csusb.edu. 


\title{
PALEOSEISMOLOGY OF THE CENTRAL GARLOCK FAULT IN SEARLES VALLEY, CALIFORNIA
}

\author{
A Thesis \\ Presented to the \\ Faculty of \\ California State University, \\ San Bernardino \\ In Partial Fulfillment \\ of the Requirements for the Degree \\ Master of Science \\ in
}

Earth and Environmental Sciences

by

Kyle Anthony Peña

December 2019 


\title{
PALEOSEISMOLOGY OF THE CENTRAL GARLOCK FAULT IN SEARLES VALLEY, CALIFORNIA
}

\author{
A Thesis \\ Presented to the \\ Faculty of \\ California State University, \\ San Bernardino \\ by \\ Kyle Anthony Peña \\ December 2019 \\ Approved by:
}

Sally McGill, Committee Chair, Geological Sciences

Joan E. Fryxell, Committee Member, Geological Sciences

Kerry D. Cato, Committee Member, Geological Sciences 
(c) 2019 Kyle Anthony Peña 


\section{ABSTRACT}

In this study, a paleoseismic trench with limited age constraints that was previously excavated in 1990 across the central Garlock Fault near Christmas Canyon, in Searles Valley, California, was reopened to take advantage of new advances in luminescence dating techniques to investigate potential temporal variability in earthquake recurrence on the Garlock Fault and to analyze previously unexposed older earthquake evidence. The trench exposed interbedded alluvial sand and pebble-gravels, with well-sorted, rounded, lacustrine sand from the most recent highstand of pluvial Lake Searles present at

the base of the trench. Preliminary findings suggest at least 10 surface rupturing earthquake events occurred during the 10 k.y. time period exposed in the trench. To provide age constraints on the paleo-surface-rupturing events from the new trench, 54 luminescence samples were collected and the single-grain luminescence dating technique post- $I R_{50}-I R S L_{225}$ was employed. The ages indicated that 7 events have occurred in the past $~ 7.2 \mathrm{ka}$, with at least 3 additional events in the more poorly stratified deeper section of the trench. This suggests a recurrence interval of $\sim 1000$ years. Event pattern seen at this trench did not exactly replicate the same pattern at other paleoseismic sites along the Garlock Fault. The most recent event seen at this trench occurred within the same time period as the most recent events seen at the other paleoseismic sites on the central Garlock Fault. 


\section{ACKNOWLEDGEMENTS}

I would like to thank my graduate advisor, Dr. Sally McGill for her continuous assistance throughout the whole thesis process. Without her support and guidance, I would not have been able to complete such a successful thesis. I would also like to thank my committee members, Dr. Joan Fryxell and Dr. Kerry Cato for their academic support and insight throughout the thesis writing process. I would like to also thank the National Science Foundation (EAR-1650364) for funding this research project.

A special thanks to the USC and CSUSB students who came out and assisted me with field work. All that work would not have been possible without your help. I would like to thank my parents for supporting me through my CSUSB journey and my future wife, Pooja, for always pushing me to strive high in both my personal and professional life. 


\section{TABLE OF CONTENTS}

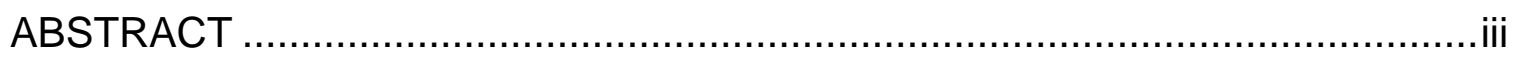

ACKNOWLEDGEMENTS ........................................................................

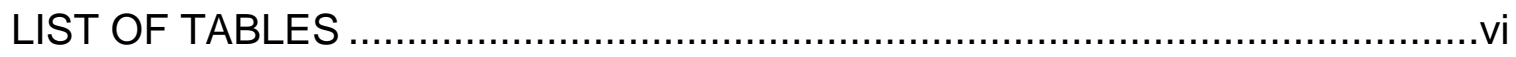

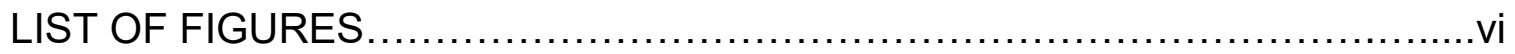

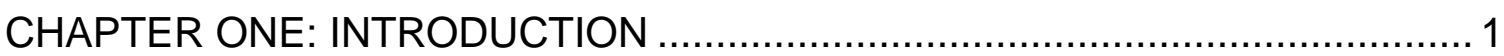

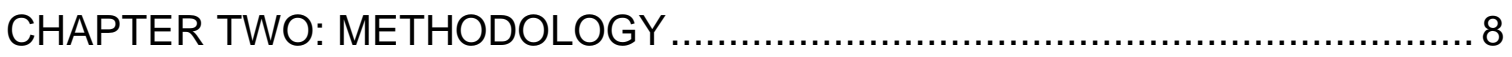

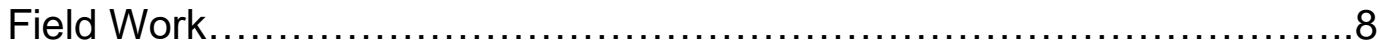

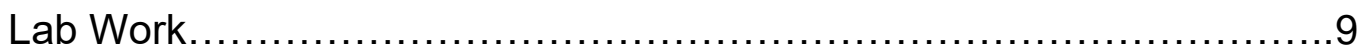

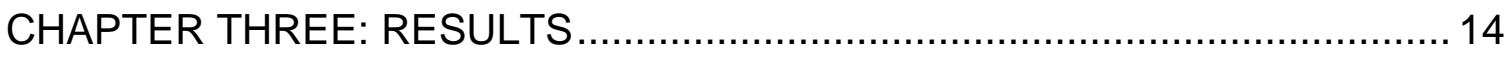

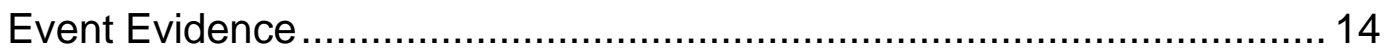

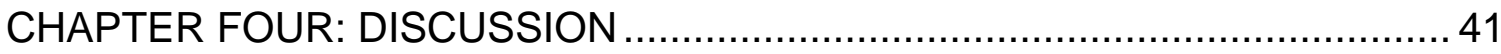

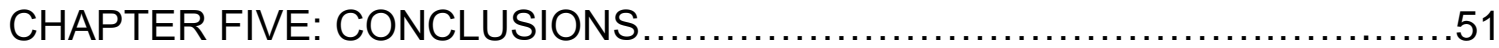

APPENDIX A: FIGURES SHOWING ALL TRENCH EXPOSURES COMBINED

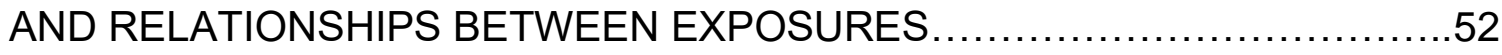

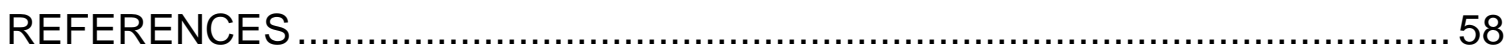




\section{LIST OF TABLES}

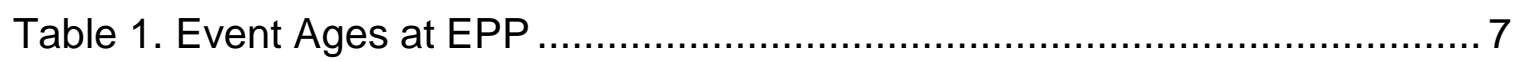

Table 2. Slip Rates of Various Studies on the Garlock Fault ............................. 7

Table 3. Criteria for Assigning Quality Rankings ......................................... 37

Table 4. Criteria for Assigning Stratigraphic Correlation Rankings................39

Table 5. Table of IRSL Samples with their Depth from Ground Surface and

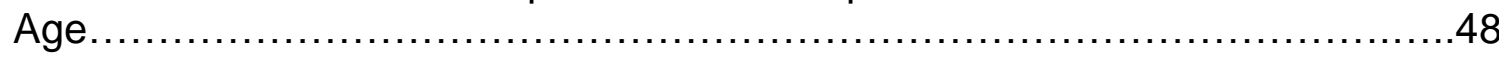

Table 6. OxCal Results Showing Unmodeled Sample Ages, Modeled Sample Ages, and Modeled Event Ages.................................................49 


\section{LIST OF FIGURES}

Figure 1. Regional map (Dolan et al., 2016). Garlock Fault (white) and other active faults (gray) around site location. White star shows location of Christmas Canyon West (CCW). White circles indicate slip-rate studies. White squares indicate paleoseismic sites. Abbreviations defined as follows: B, Barstow; CW, Clark Wash; EPP, El Paso Peaks; KL, Koehn Lake; M, Mojave; R, Ridgecrest; SLR, Slate Range site; SLS, Searles Lake Shoreline; SR, Summit Range site; T, Trona; TL, Twin Lake site; W, Wrightwood. .5

Figure 2. Published ages of surface rupturing earthquake events from paleoseismic studies along the Garlock Fault compared to the CCW 2018 event ages. CW, Clark Wash (McGill et al., 2009); EPP, El Paso Peaks (Dawson et al., 2003); KL, Koehn Lake; SLR, Slate Range site; EP, Echo Playa (Kemp et al., 2016); SLS, Searles Lake Shoreline; SR, Summit Range site; TL, Twin Lake site

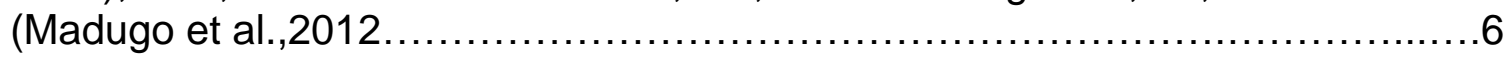

Figure 3. Lidar image showing north and south end of the trench in this study, which is represented by two dots connected with thick white line, relative to Garlock Fault. The Garlock Fault trace is shown with a thin white line in places where the fault trace is faint.

Figure 4. Overview picture of trench showing upper tier and deep slot with hydraulic shoring.

Figure 5. Photomosaic of the east wall upper tier showing the event 1 (yellow horizon), event 2 (pink horizon) event 3 (light blue horizon), event 4 (green horizon), event 5 (orange horizon), event 6 (purple horizon), event 7 (yellowgreen horizon), event 8 (dark yellow horizon), and event 9 (dark blue horizon) horizons. In the upper tier, the extent of the yellow, blue, and orange horizons can be seen. Grid is one meter with no vertical exaggeration. Filled orange circles mark locations of luminescence samples that were collected.

Figure 6. Photomosaic of the west wall showing an overview of the main fault zone of the upper tier and the deep slot. Yellow, light blue, green, orange and dark blue lines mark the event 1 , event 3 , event 4 , event 5 and event 9 horizons, respectively. 
Figure 7. Enlarged view of the fault zone (21-28 $\mathrm{m}$ ) within the upper tier on the east wall showing evidence for events 1-7. Colored lines mark earthquake horizons and stars mark locations of evidence for events. Event 1: yellow; Event 2: pink; event 3: light blue; event 4: green; event 5: orange; event 6: purple; event 7: yellow green. Refer to text for alternate interpretations of event 5 horizon, shown by dashed and dotted orange lines. No vertical exaggeration. Dashed yellow line near fault 1 is marking the $25-\mathrm{cm}$-thick pebble layer that was folded.

Figure 8. Enlarged view of the fault zone (17-23 $\mathrm{m}$ ) within the upper tier on the west wall showing evidence for events 1,4 , and 5 at locations of yellow, green and orange stars. No vertical exaggeration....

Figure 9. Photomosaic showing a portion of the fault zone $(22-17 \mathrm{~m})$ within the deep slot on the east wall, showing evidence for events 8 (dark yellow horizon and star) and 9 (dark blue horizon and stars)

Figure 10. Photomosaic showing a portion of the fault zone (19-24 $\mathrm{m})$ within the deep slot on the west wall showing evidence for event 9 (dark blue horizon).....35

Figure 11. Older thrust event (dark blue horizon) showing colluvial wedge deposited on top of a flat-lying silty sand layer within the deep slot on the east wall.

Figure 12. Age versus stratigraphic depth of IRSL samples. Horizontal red lines indicate the approximate stratigraphic depth of event horizons. Vertical red lines represent the interpolated ages of events based on their stratigraphic depth between dated samples.

Figure 13. OxCal model showing sample and event probability density functions before and after Bayesian approach was used to reweight the probability density functions. 


\section{CHAPTER ONE}

\section{INTRODUCTION}

The Garlock Fault (GF) is a significant left-lateral strike-slip fault in California, that strikes broadly east-west (Figure 1). It is about $250 \mathrm{~km}$ in length and extends from its intersection with the San Andreas Fault on the west through Death Valley on the east. The maximum documented left-lateral displacement is 48-64 km (Smith, 1962; Smith and Ketner, 1970; Davis and Burchfiel, 1973; Carr et al., 1992; Monastero et al., 1997). The GF initiated between 9 and 10 Ma with the rotation of the El Paso basin (Burbank and Whistler, 1987; Loomis and Burbank, 1998). On the basis of fault geometry (bends, major step-overs, fault intersections) McGill and Sieh (1991) divided the GF into three separate sections consisting of the western section, the central section, and the eastern section that are $100 \mathrm{~km}, 105 \mathrm{~km}$, and $55 \mathrm{~km}$ in length, respectively. The Christmas Canyon study site is located in the middle section of the GF.

The GF has not produced any major surface rupturing events during recorded history. Because of this, what is known about events along the GF come from paleoseismic studies, with most of the data coming from the central section of the fault. Studies by Burke and Clark (1978) and Burke (1979) describe evidence of 9-17 events within the last $14,700 \pm 130$ years, at a site near Koehn Lake based on radiocarbon dating of ostracods from the base of the trench, which makes the recurrence interval 860-1600 years, but had no constraints on individual events. McGill (1992) was able to document 4 events at 
a site west of Christmas Canyon and showed that the most recent event (MRE) occurred within the last 207-527 years, but no age constraints were available for the older events. The El Paso Peaks paleoseismic site yielded evidence for five well-resolved events during the last 5000 years (McGill and Rockwell, 1998).

Dawson et al. (2003) re-opened and deepened the trench previously excavated by McGill and Rockwell (1998), extending the paleoseismic record by 2000 years back to $7000 \mathrm{BP}$. They identified six surface rupture events, four of which occurred in the past 2 ka (cluster), preceded by 3000 years of no earthquakes (lull), then two more events occurring at $\sim 5 \mathrm{ka}$ and $7 \mathrm{ka}$ (Figure 2 and Table 1). Kemp et al. (2016), found evidence for four events at the Echo Playa paleoseismic site. The events were dated at 1615-1820 CE, 470-730 CE, 40$150 \mathrm{CE}$, and 275-1950 BCE (Figure 2).

On the western section of the GF at Twin Lakes, Madugo et al. (2012), also found evidence for up to six events. These events were dated at $1450 \mathrm{CE}$, 720-395 BCE, and 3425-2200 BCE for events A, G, and I, respectively Figure 2). Two other possible events were constrained to $625-1525 \mathrm{CE}$, and $155 \mathrm{BC}-614$ $\mathrm{CE}$ for events $\mathrm{C}$ and $\mathrm{E}$, respectively. The MRE on the western section and the MRE on the central section likely correlate, which suggests that both sections can rupture at the same time producing large earthquakes (Madugo et al., 2012).

Several slip rate studies along the GF have resulted in similar slip rates since the late Pleistocene-early Holocene of $\sim 5$ to $\sim 8 \mathrm{~mm} / \mathrm{yr}$ for the central and western parts of the fault (Table 2) (Clark and Lajoie, 1974; McGill and Sieh, 1993; McGill et al., 2009; Ganev et al., 2012;). A slip rate of 7.6 +3.1/-2.3 mm/yr 
was reported at Clark Wash (McGill et al., 2009), which is $30 \mathrm{~km}$ west of Koehn Lake. McGill et al. (2009), calculated this rate by radiocarbon dating a $66 \pm 6 \mathrm{~m}$ offset of an incised channel. Clark and Lajoie (1974) measured a lacustrine berm from Koehn Lake that has been offset $80 \pm 5 \mathrm{~m}$ and dated tufa from the berm using radiocarbon dating to obtain a slip rate of 5-8 mm/yr. Ganev et al. (2012), recalculated this slip rate to be $\sim 5.0-7.7 \mathrm{~mm} / \mathrm{yr}$ using the most up-to-date calibration of the radiocarbon time scale. On the eastern part of the central section, McGill and Sieh (1993) calculated a slip rate of 4-9 mm/yr, with a preferred rate of 5-7 mm/yr, using an offset of a latest Pleistocene Searles Lake shoreline. Organic sediment from lake beds within cores from the center of Searles Valley (Struiver and Smith, 1979) and oolites and mollusks from shoreline features (Benson et al., 1990) were radiocarbon dated to constrain the age of the most recent lake stand.

In contrast, estimates of the Late Holocene slip rate have been faster. Rittase et al. (2014), estimated a slip rate of $\sim 11-13 \mathrm{~mm} / \mathrm{yr}$ for the late Holocene using OSL ages of an offset fan. A high late Holocene slip rate on the central GF was confirmed Dolan et al. (2016). In this study a late a slip rate of $14.0+2.2 /-$ $1.8 \mathrm{~mm} / \mathrm{yr}$ was estimated using the youngest post-IR-IRSL date $(1860 \pm 150$ years before 2013) from an alluvial fan offset $~ 26 \mathrm{~m}$ (Dolan et al., 2016). The cluster and lull pattern seen at the El Paso Peaks site (Dawson et al., 2003) suggest that the GF is not slipping continuously or is not slipping at a constant rate. This conclusion is supported by both Rittase et al. (2014) and Dolan et al. (2016) that show a varying slip rate throughout the Holocene. 
The recent work on the GF suggests that a simple earthquake cycle model with earthquakes repeating at regular intervals may not apply to this part of the GF. This hypothesis was tested by reopening the paleoseismic trench that was initially investigated by McGill (1992) at a site at west of Christmas Canyon, (here called the Christmas Canyon West, or CCW site) (Figure 1 and 3). The trench was also deepened in order to extend the paleoseismic record to farther back in time to compare earthquake event patterns to those documented at El Paso Peaks over the past 7000 years. The aim of this study was to address the following questions: (1) Does this section of the GF display a cluster and lull behavior as was observed at the El Paso Peaks site (Dawson et al., 2003)?; (2) Can the ages of the paleoearthquakes dated in the CCW trench be correlated with paleoearthquakes documented at El Paso Peaks (Dawson et al, 2003) and/or Echo Playa (Kemp et al., 2016); and what implications does this have for the rupture lengths of past earthquakes? By constructing a detailed paleoseismic record on the GF at the CCW site and comparing event ages with the ages of other events found at previous paleoseismic sites, this study will help to clarify the earthquake recurrence behavior of the Garlock Fault and may shed light on fault system dynamics in addition to further developing the seismic hazard model for California. 


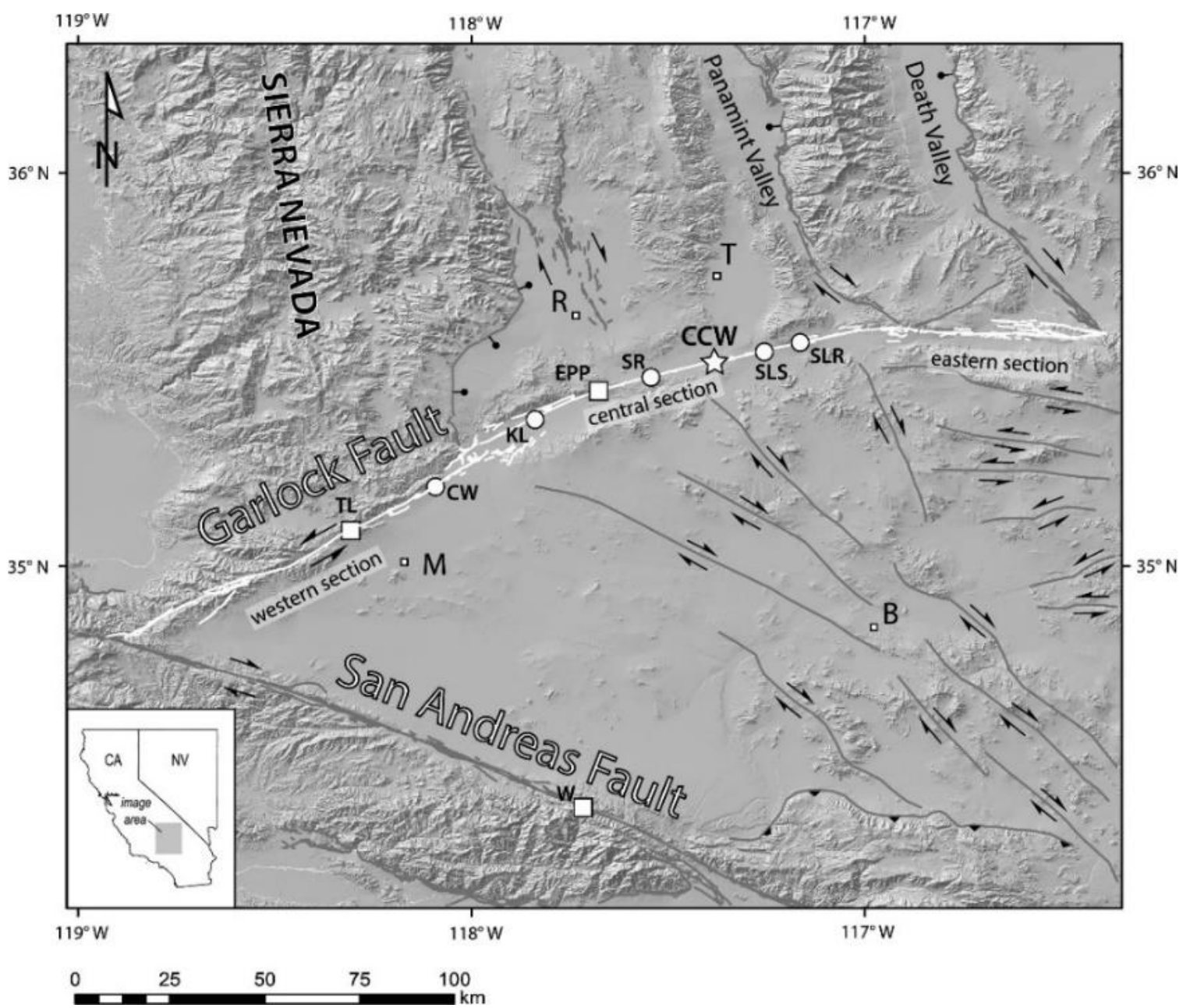

Figure 1. Regional map (Dolan et al., 2016). Garlock Fault (white) and other active faults (gray) around site location. White star shows location of Christmas Canyon West (CCW). White circles indicate slip-rate studies. White squares indicate paleoseismic sites. Abbreviations defined as follows: B, Barstow; CW, Clark Wash; EPP, El Paso Peaks; KL, Koehn Lake; M, Mojave; R, Ridgecrest; SLR, Slate Range site; SLS, Searles Lake Shoreline; SR, Summit Range site; T, Trona; TL, Twin Lake site; W, Wrightwood. 


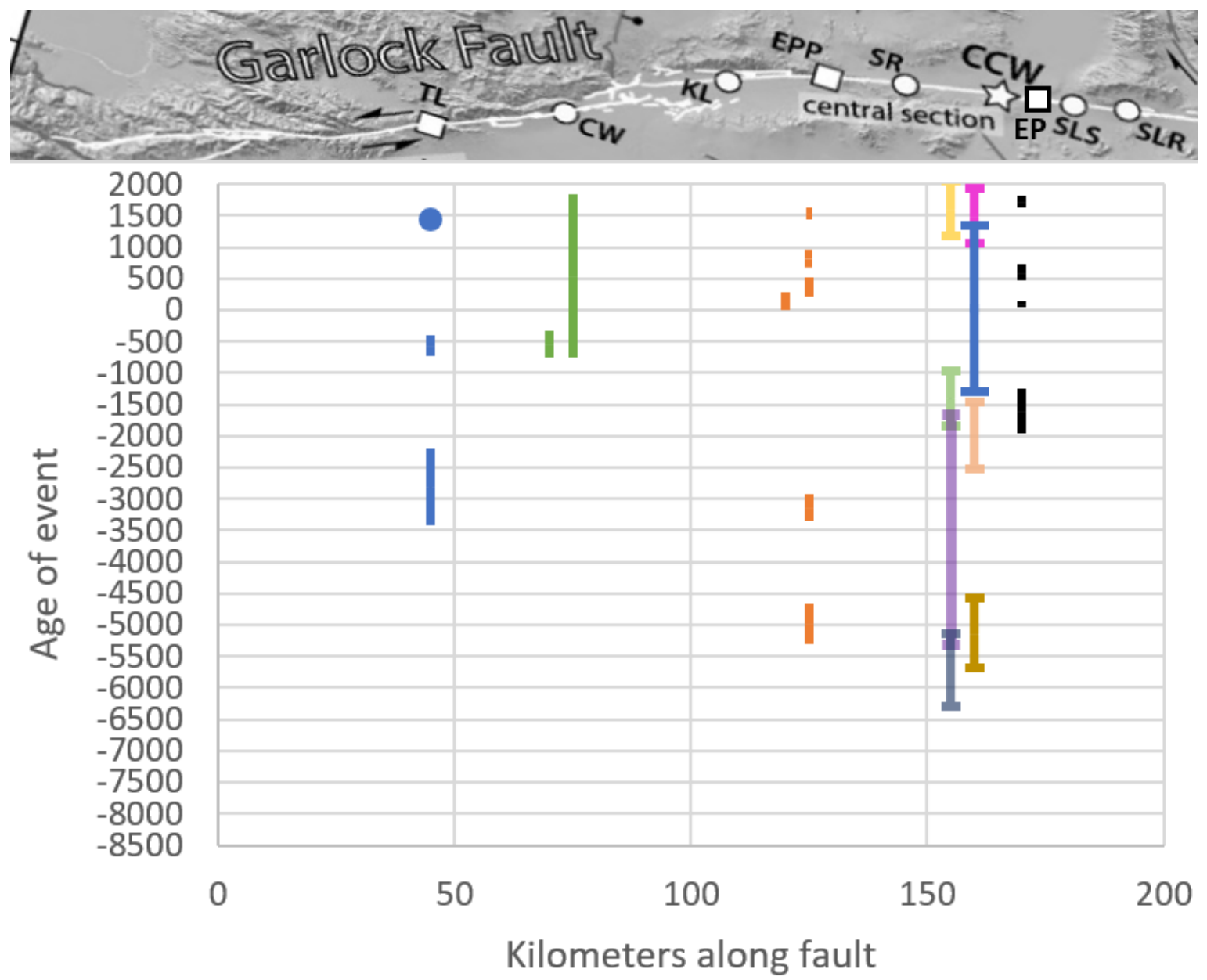

Figure 2. Published ages of surface rupturing earthquake events from paleoseismic studies along the Garlock Fault compared to the CCW 2018 event ages. CW, Clark Wash (McGill et al., 2009); EPP, El Paso Peaks (Dawson et al., 2003); KL, Koehn Lake; SLR, Slate Range site; EP, Echo Playa (Kemp et al., 2016); SLS, Searles Lake Shoreline; SR, Summit Range site; TL, Twin Lake site (Madugo et al., 2012). 
Table 1. Event Ages at EPP

\begin{tabular}{ll}
\hline \hline Event & Age \\
\hline W & $1450-1640 \mathrm{CE}$ \\
U & $675-950 \mathrm{CE}$ \\
$\mathrm{R}$ & $250-475 \mathrm{CE}$ \\
$\mathrm{Q}$ & $25-275 \mathrm{CE}$ \\
$\mathrm{K}$ & $3340-2930 \mathrm{BCE}$ \\
$\mathrm{F}$ & $5300-4670 \mathrm{BCE}$
\end{tabular}

Dawson et al., 2003

Table 2. Slip Rates of Various Studies on the Garlock Fault

\begin{tabular}{ll}
\hline \hline Study & Slip Rate $(\mathrm{mm} / \mathrm{yr})$ \\
\hline McGill et al., 2009 & $7.6+3.1 /-2.3$ \\
Clark and Lajoie 1974 & $5-8$ \\
Ganev et al., 2012 & $5.0-7.7$ \\
McGill and Sieh 1993 & $5-7$ \\
Dolan et al., 2016 & $14+2.2 /-1.8$ \\
Rittase et al., 2014 & $11-13$ \\
\hline
\end{tabular}




\section{CHAPTER TWO \\ METHODOLOGY}

\section{Field Work}

The new study deepened and widened the original trench at the Christmas Canyon West site (465034.5 E, 3930812 N), which was located on U.S. Navy property within alluvial fan deposits (Figure 3). The original trench excavated in 1990 was $2.7 \mathrm{~m}$ deep. The trench was reopened in two phases. First, a $1 \mathrm{~m}$ wide, $1.5 \mathrm{~m}$ deep trench coinciding with the uppermost $1.5 \mathrm{~m}$ of the 1990 trench was excavated, photographed and the walls logged. Secondly, the width of the trench was increased to about $3 \mathrm{~m}$ at this same $1.5 \mathrm{~m}$ depth and then a $1 \mathrm{~m}$ wide excavation was made below this level that extended the trench depth to a maximum of $4 \mathrm{~m}$ beneath the ground surface. This resulted in a two-tiered trench, with a $\sim 1.5 \mathrm{~m}$ tall upper tier separated from $\mathrm{a} \sim 2.3 \mathrm{~m}$ tall lower tier, which was referred to as the "deep slot" (Figure 4).

The trench exposed Holocene alluvial fan deposits including stratified coarse sand, pebbly sand, or silty pebbly sand, ranging from moderately sorted and grain-supported to poorly sorted and matrix-supported. A few cobbly lenses were present in some units. The grain-supported units were interpreted as alluvial stream deposits and the matrix-supported layers as hyper-concentrated flow deposits. At the base of the trench, up to $20 \mathrm{~cm}$ of well-sorted medium to coarse sand with rounded grains was exposed, and these deposits were interpreted as nearshore lacustrine sand from the most recent high stand of 
Searles Lake. The trench also exposed a fault-bounded sliver of older, wellconsolidated sand and gravel with tilted stratigraphy (see Figure 5, between faults 3 and 4 in the upper tier and between faults 45 and 46 in the lower tier; see Figure 6, between faults 39 and 40 in the upper tier and between 80-84 in the lower tier). It was interpreted that this was a sliver of an older alluvial fan deposit that has been laterally and/or vertically transported within the fault zone.

Numbered nails were placed at 1-meter intervals along the top and bottom of each tier the trench to make a grid and were surveyed with a Wild TC 1010 total station. The trench walls were then photographed and photomosaics were constructed using Agisoft Photoscan, using the surveyed nails to georeference the photomosaics. In the field, sedimentary contacts and faults were annotated on printed copies of the preliminary mosaics, as well as the locations of samples collected for dating and interpretations made in the field.

Samples for luminescence dating were collected in thin-walled metal tubes that were pounded into the trench wall at locations selected to constrain the ages of earthquake event horizons. Fifty-four samples were collected for luminescence dating, of which fourteen samples have been dated. Because the ends of the tubes could have been exposed to light, $3 \mathrm{~cm}$ of sediment at each end were not used in the dating process.

\section{Lab Work}

Luminescence dating uses a crystal's luminescence signal that is built up within the crystal lattice through time. The luminescence signal is accumulated when the crystal is exposed to the natural radiation when the crystal is buried 
beneath sediment. If a crystal is exposed to light, then the luminescence signal is emitted, and the signal is reset (Aitken, 1998). By recording the natural radiation of the sediment where a sample is collected and then exposing the crystal to light within a controlled environment, scientists can determine how long the crystal has been buried. To determine the age of the sample, each mineral grain has its natural luminescence recorded and then is irradiated with different doses of radiation and then retested for luminescence. From this, a graph is made that shows how much radiation the grain was subjected to and the luminescence corresponding to that radiation dose. This can then be compared to the radiation of the sediment where the sample was collected to determine how long the sample grain took to accumulate the amount of radiation necessary to produce the natural dose that was first measured from the sample (Murray and Wintle, 2000).

This study used the recently developed post-IR $\mathrm{I}_{50}-\mathrm{IRSL}_{225}$ single grain luminescence protocol on potassium feldspar grains (Rhodes, 2015). Post-IR ${ }_{50}$ $\mathrm{IRSL}_{225}$ first bleaches the sample with infrared (IR) photons at 50 degrees Celsius, then takes infrared stimulated luminescence (IRSL) readings at 225 degrees Celsius. The initial bleaching removes the portion of the signal that is less stable.

Samples were prepared at UCLA's luminescence lab. Sample tubes were opened inside the lab, which was lit by dim orange LED lights, to minimize exposure of the samples to light. About $3 \mathrm{~cm}$ of each end of the tube was removed because that material could have been exposed to light during 
collection, which would have released any stored luminescence. The $3 \mathrm{~cm}$ removed from each side was weighed and then put into a conventional oven to dry, the dry sample was then weighed to calculate the water content of each sample. The remaining sample was wet sieved to separate the sample into different sieve fractions. The 175-200-micron sieve fraction was used for this study. Each sieve fraction was then put into the oven to dry. After drying, each sieve fraction was put into a plastic bag, labeled, and then put into a light-proof bag. Using the 175-200-micron sieve fraction, potassium feldspar grains were separated from other mineral grains by density. The density separation was accomplished using Lithium Metatungstate (LMT), at a density of 2.565 that was provided by the UCLA lab. A few grams of the sample were added to the LMT and then shaken by hand to help the sample mix into the LMT before putting the sample into a centrifuge to further separate the grains. The bottom tip of the sample tube was then submerged in liquid nitrogen to freeze the LMT and higher density sample grains on the bottom, so that the LMT and lower-density sample grains at the top can be poured out. The grains of each density were saved, but only the lower density (potassium feldspar) grains were used in the post-IR ${ }_{50^{-}}$ $\operatorname{IRSL}_{225}$ dating. 


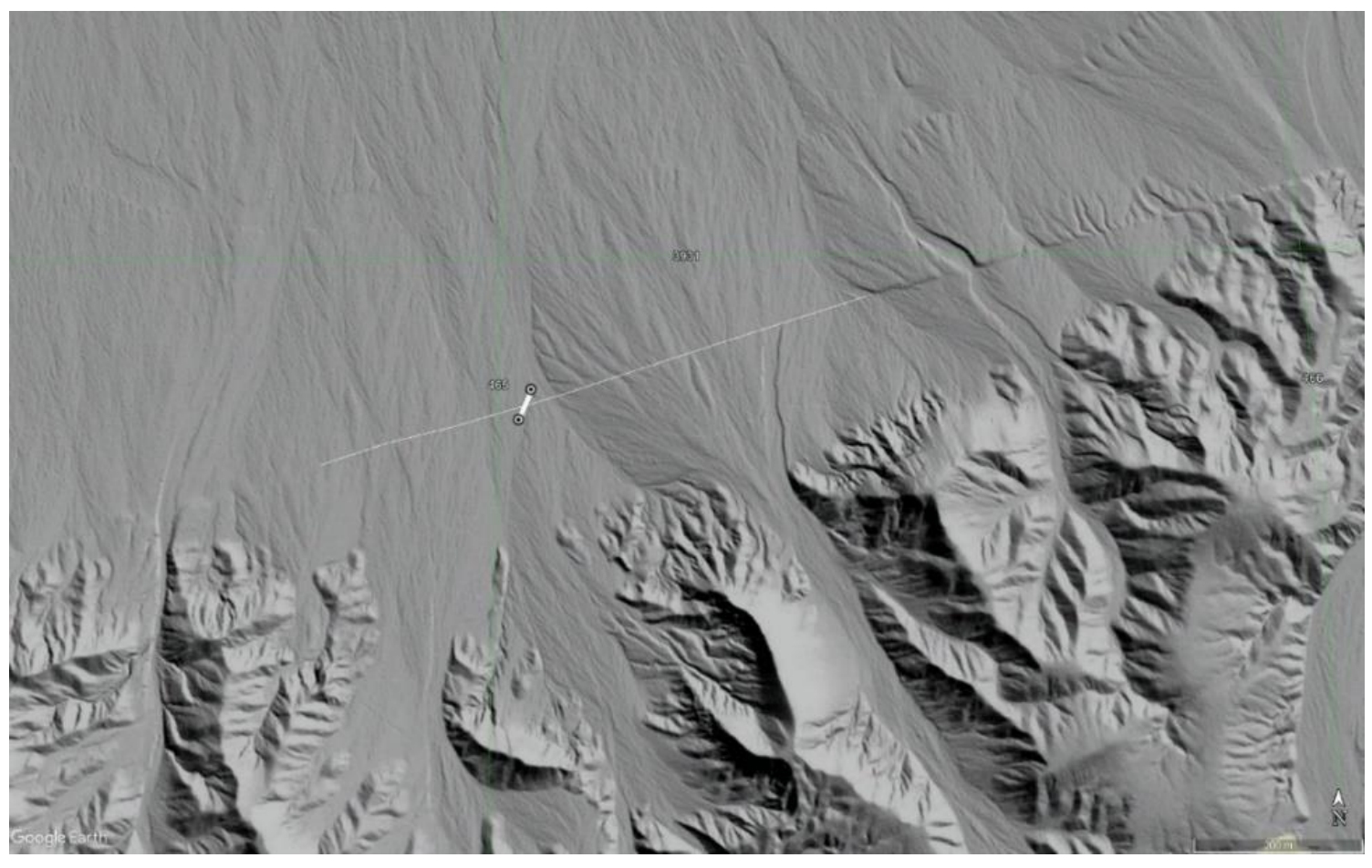

Figure 3. Lidar image showing north and south end of the trench in this study, which is represented by two dots connected with thick white line, relative to Garlock Fault. The Garlock Fault trace is shown with a thin white line in places where the fault trace is faint. 


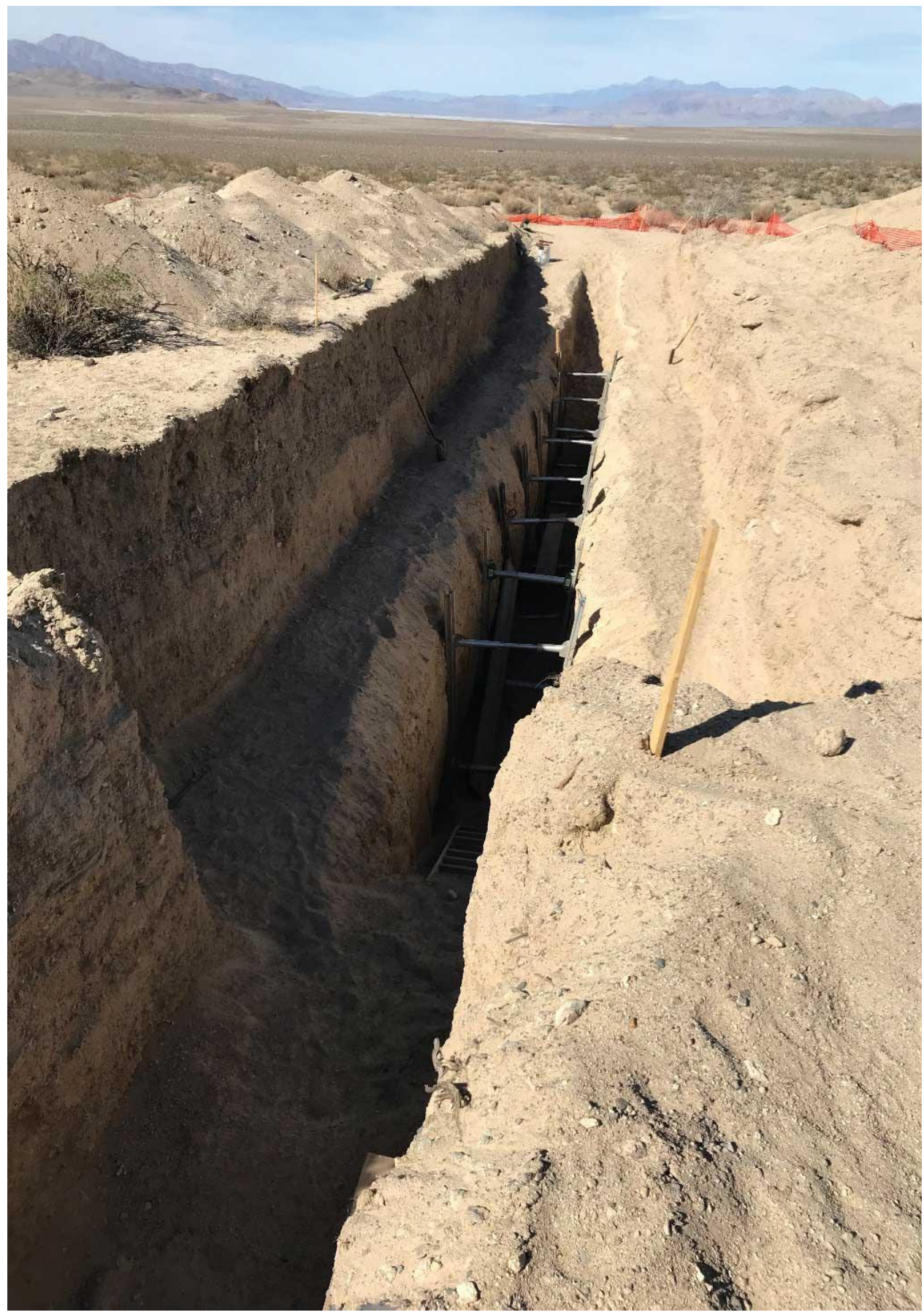

Figure 4. Overview picture of trench showing upper tier and deep slot with hydraulic shoring. 


\section{CHAPTER THREE}

RESULTS

\section{Event Evidence}

On the east and west walls, there is potential evidence for eleven events (Figure 5 and 6). A quality ranking was given to each event indicator based on the strength of structural and sedimentological evidence that was used to identify the stratigraphic unit that was at the ground surface when the event occurred (Table 3). Each indicator was given a quality rank on a scale of 0 to 5 with higher numbers indicating stronger evidence. This ranking system was modified from (Scharer et al., 2017 and Castillo, 2019), with modifications and clarifications specific to the CCW trench. A stratigraphic correlation scale was used that evaluates how well each piece of evidence for a particular event can be correlated with the type locale for that event (Table 4). This ranking uses a scale of 0 to 5 where a higher number indicates a stronger correlation. The event indicator with the highest quality rating for any particular event was defined as the type locale for that event and received a stratigraphic correlation ranking of 5 .

\section{Event 1}

There are 8 fault strands on the east wall that clearly rupture up to but not above the yellow horizon (fault strands 4, 5, 6,12, 16, 17, 18 and 20) (Figure 9). Fault strand 12 at $24 \mathrm{~m}$ on the east wall offsets the blue horizon by about $6.6 \mathrm{~cm}$, and truncates the pink horizon, but does not rupture the yellow horizon. The strand terminates a few centimeters below the yellow horizon. The quality rating 
for this strand is 3 because this fault has distinct upward termination and has moderate offset. This event indicator is our type locale for event 1 and therefore has a stratigraphic correlation of 5 . The pink horizon defines the base of a hyperconcentrated flow deposit and is interpreted as being at the ground surface at the time of event 2 (see below), therefore faults that offset the pink horizon are attributed to event 1 . Fault strand 16 near $23 \mathrm{~m}$ on the east wall, offsets the blue horizon by $12 \mathrm{~cm}$ and offsets a probable continuation of the pink horizon by 15.5 $\mathrm{cm}$ and terminates $10 \mathrm{~cm}$ below the yellow horizon (quality rating 3 ). Fault strands 17 and 18 near $23 \mathrm{~m}$ on the east wall, together offset the blue horizon about $11 \mathrm{~cm}$ and terminate 10 and $16 \mathrm{~cm}$ below the yellow horizon (quality rating 3). These two faults also offset the pink horizon. Fault strand 20 at $22.5 \mathrm{~m}$ on the east wall, offsets the blue horizon about $8 \mathrm{~cm}$ and terminates about $10 \mathrm{~cm}$ below the yellow horizon (quality rating 3 ). These indicators (faults 16, 17, 18 and 20) are each given a stratigraphic correlation of 4 because of minor uncertainty of the location of pink horizon.

In addition, at fault strand 1, to the north of the bedrock sliver on the east wall, a $25-\mathrm{cm}$-thick pebble layer has been folded into a 45-cm-high fold, which has been buried by colluvium (Figure 7). The sharp kinks in this layer at faults 1 and 3 seem unlikely to be explained by deposition of this layer over an uneven surface. This indicator has a quality rating of 3 due to substantial folding and possible colluvial fill on the down-folded side. The dashed yellow horizon that marks the top of the folded pebble layer interpreted as the event horizon. This horizon may correlate with the yellow, Event 1, horizon south of the bedrock 
sliver, but it is also possible that the strata north of the bedrock sliver have been uplifted by vertical slip on faults 3-6 and may be older than the strata south of the bedrock sliver. This event indicator is tentatively associated with event 1 but is given a correlation rating of 1 due to the impossibility of correlating strata across faults 3-6.

There are 10 fault strands that terminate below the yellow horizon and may be attributed to either event 1,2,3, or 4 depending on the interpretation of event horizons (Figure 7 and 8). Fault strands 4, 5, and 6, just south of the bedrock sliver on the east wall, break the blue horizon and continue up to the approximate level of the yellow horizon which is indistinct in this area (quality rating 1). The pink horizon cannot be traced this far north, so it is unclear whether these faults last slipped in event 1 or in event 2 (stratigraphic correlation rating 1 ). On the west wall at $18-19 \mathrm{~m}$, fault strands 25 and 26 offset the blue horizon about $10 \mathrm{~cm}$ and terminate 21 and $33 \mathrm{~cm}$ below the yellow horizon (quality rating 1). There is uncertainty in these strands being event 1 or event 2 because the faults terminate significantly below the yellow horizon and because the pink horizon is not present. Due to the lack of pink horizon at this location, these fault strands have a stratigraphic correlation of 1 . Fault strands 28 and 29 at $19.0-18.5 \mathrm{~m}$ on the west wall, offset the blue horizon $7 \mathrm{~cm}$ and terminate below the yellow horizon (quality rating 3 ). These faults terminate 8 and $0 \mathrm{~cm}$ below the yellow horizon, respectively. However, the yellow horizon is cutting down in this section and may have scoured away the strata that would potentially correlate with the event 2 horizon on the east wall, so this evidence could be for 
either event 1 or event 2 (quality rating 1). The absence of the pink horizon on the west wall also makes it impossible to distinguish between events 1 and 2 on the west wall, therefore these faults have a stratigraphic correlation of 1. Fault strands 36 and 37 at $23.5 \mathrm{~m}$ on the west wall, cut the green horizon and terminate at the yellow horizon. These strands could be associated with events 1,2 , or 3 because it is uncertain whether these faults offset the blue or the pink horizons before they were scoured away by the channel that has the yellow horizon at its base (quality rating 0 ). These indicators were not given a stratigraphic correlation rating because it is not certain to which event they belong. Fault strand 39 at $25 \mathrm{~m}$ on the west wall, along the south edge of the bedrock sliver, creates a $13 \mathrm{~cm}$ offset of a contact between a thick massive unit below and a grain-supported unit above. This contact is below the scour surface that has the yellow horizon at its base. This offset contact may correlate with the orange horizon seen elsewhere throughout the trench and interpreted as the event 5 horizon. Fault 39 clearly offsets the contact but becomes less distinct above the contact and does not offset the yellow horizon. Because of the uncertainty in stratigraphic correlation across faults $36-38$, and because of the erosive nature of the channel with the yellow horizon at its base, this fault could be associated with events $1,2,3$, or 4 (quality rating 0 ). This indicator was not given a stratigraphic correlation rating because the erosive nature of the yellow scoured contact makes it unclear with which event horizon a correlation should be sought 


\section{Event 2}

Event 2 is represented by fault strand 30 at $20.5 \mathrm{~m}$ on the west wall offsets the orange horizon (Event 5, see below, Figure 8) $16 \mathrm{~cm}$ and terminates 8 $\mathrm{cm}$ below the yellow horizon (Event 1). This fault has moderate offset with a distinct upward termination at the base of silty hyper-concentrated flow deposit flow (quality rating 3 ). The unfaulted, silty hyper-concentrated flow deposit is located a few centimeters below the yellow horizon, indicating that this event must pre-date event 1 . The blue horizon (Event 3) has been tentatively identified along the base of a grain-supported layer that is truncated by fault 30 . Therefore, this fault appears to post-date event 3. Therefore, this fault, which pre-dates event 1 and post-dates event 3 , is the type locale for event 2 and is therefore a stratigraphic correlation rating of 5 . Fault strand 31 at $21 \mathrm{~m}$ on the west wall (Figure 8) offsets the orange horizon $20 \mathrm{~cm}$ and terminates $12 \mathrm{~cm}$ below the yellow horizon (quality rating 3 ). Like fault 30 , fault 31 also terminates abruptly at the base of a thin, silty hyper-concentrated flow deposits that is located a few centimeters below the yellow horizon. This indicator is given a stratigraphic correlation rating of 5 because it has the same capping layer as the type locale for this event. Fault strand 13, on the east wall (Figure 7), terminates upward below the pink horizon, which is at the base of a hyper-concentrated flow deposit at $24 \mathrm{~m}$ on the east wall. Fault strand 13 extends above the blue horizon but terminates below the pink horizon (quality rating 2 ). This event is clearly distinct from event 1 in the vicinity of location (a), because fault 13 at location (a) does not offset the pink horizon, whereas, fault strand 12 , a few centimeters to the 
north, does truncate the pink layer. This indicator is given a stratigraphic correlation rating of 4 because it is on the opposite wall of the type locale for event 2. Fault strands 12 and 13 together produced $17 \mathrm{~cm}$ of vertical separation in events 1 and 2 combined. Therefore, moderate slip ( $>5 \mathrm{~cm}$ in any direction) on this strand seems likely.

\section{Event 3}

The type locale for Event 3 is a small fissure at location (i) at $26 \mathrm{~m}$ on the east wall (Figure 7) which is capped by a sharp contact (blue horizon) at the base of a grain-supported layer (quality rating 4 ). No contacts can be correlated across faults 6 and 7 , suggesting that lateral slip is at least moderate. The top of the fissure is distinct, as is the upward termination of fault strand 7 at the blue horizon on the south side of the fissure. The fissure is filled with massive material that does not clearly post-date the inferred event horizon, therefore the possibility that this is a zone of distributed slip cannot be ruled out. Nonetheless, the upward broadening shape is consistent with interpretation as a fissure. On the east wall evidence for event 3 was found at $22-26 \mathrm{~m}$, but on the west wall the blue horizon has been scoured away by the yellow horizon at these locations (Figure 6). The blue horizon is a continuous contact with grain-supported material above and matrix-supported material with granule clasts below that was seen on both east and west walls (Figure 6). Therefore, evidence for event 3 is limited or missing on the west wall. One event indicator that may represent event 3 on the west wall is fault strand 33 , at $21.5 \mathrm{~m}$ (Figure 8). This strand offsets the orange horizon at $16 \mathrm{~cm}$, truncates the green horizon, and terminates at or just 
below the yellow horizon, which has scoured away the blue horizon. The fault can only be traced upward to within a few $\mathrm{cm}$ below the yellow horizon. If the fault extends all the way up to the yellow horizon (despite not being clearly visible here), this could be events 1,2 , or 3 ; if the fault stops a few $\mathrm{cm}$ below yellow (despite the lack of a clear capping horizon), this would be event 4. Therefore, this event indicator has a quality rating of zero. Due to the great uncertainty to which event this strand belongs, this indicator was not given a stratigraphic correlation rating. Fault strand 38 at $23.5-25 \mathrm{~m}$ on the west wall terminates $\sim 5-$ $10 \mathrm{~cm}$ below the yellow horizon (Figure 8). Therefore, it is older than event 1, but it is unclear how much older, due to indistinct upward termination, as well as difficulties in correlating strata across faults 36 and 37. Therefore this indicator has a quality rating of zero, which resulted in not giving a stratigraphic correlation.

Another potential piece of evidence for event 3 (or 4 ) is an angular unconformity at location (g), at $22.5 \mathrm{~m}$ on the east wall (Figure 7). Here layers below the blue horizon are tilted and the blue horizon itself is not tilted. The precise stratigraphic level of the angular unconformity is unclear. The tilting could have occurred during either event 3 or 4 . Because of this uncertainty, this indicator has a quality rating of 0 , and is not assigned a stratigraphic correlation rating. 


\section{Event 4}

Event 4 is represented by a fissure (e) at $23 \mathrm{~m}$ on the east wall (Figure 7), capped by the base of a silty hyper-concentrated flow deposit (green horizon). It is also possible that this silty deposit is part of the fissure, rather than being a hyper-concentrated flow deposit, and thus the fissure could extend up to the blue horizon and could have formed in event 3 (Figure 7). However, our preferred interpretation is that there is a through-going hyper-concentrated flow deposit, which caps the fissure at the level of the green horizon. Given the mild uncertainty in the location of the top of the fissure, this indicator is given a quality rating of 3 . This indicator is the type locale for event 4 and is thus given a stratigraphic correlation of 5 .

At $22.5 \mathrm{~m}$ on the west wall faults 34 and 35 at location (e) offset the orange horizon and are capped by a sharp contact below the yellow horizon (Figure 8). Because of the stratigraphic distance between the top of the fault strands and the overlying unfaulted horizon, this indicator is given a quality rating of 2. This unfaulted horizon is probably stratigraphically below the blue horizon because at $20.5 \mathrm{~m}$ the yellow horizon scours down below the blue horizon and this horizon is not stratigraphically high enough to be the blue horizon. Because this event horizon is shortly above the orange horizon, which can be correlated with certainty between the two trench walls, at least in the southern half of the trench, and was interpreted as correlating with the green horizon (event 4) on the east wall and give a stratigraphic correlation of 3 to this indicator. There is 
some added uncertainty of the correlation of the orange contact across fault 33 , which leads to a stratigraphic correlation ranking of 3, rather than 4 .

\section{Event 5}

There are multiple lines of evidence for event 5 (orange horizon). The orange horizon is a distinctive contact between a thick (up to $1 \mathrm{~m}$ ), matrixsupported unit below and grain-supported sand and granules above (Figure 5 and 6). This distinctive contact was seen throughout most of the upper tier on both walls of the trench, and there is confidence of its correlation between the two walls. The strongest indicator (and type locale) is the upward termination of fault 15 below the solid orange horizon at $23.5 \mathrm{~m}$ (d1) (quality rating 2). Several faults with minor displacement $(8,9,10,11)$ are capped by a sharp contact (orange horizon) at $25.5 \mathrm{~m}(\mathrm{~h} 1, \mathrm{~h} 2), 24.7 \mathrm{~m} \mathrm{(g),} 24.3 \mathrm{~m}(\mathrm{~b})$ on the east wall (quality rating 1 ). These 4 faults all clearly terminate at the same level. There are several possible correlations of the orange horizon across fault 12 and 13 at 24 m. In Figure 7 the solid orange contact shows the preferred correlation, and the dashed and dotted lines show alternate correlations. In the preferred correlation the upward termination of faults 8-11 provide supporting evidence for event 5 . However, if the solid orange horizon north of faults $12-13$ correlates with the dashed orange horizon to south, then the upward termination of faults $8-11$ would represent an older event than the one at d1. Due to this uncertainty, the event indicators $\mathrm{h} 1, \mathrm{~h} 2, \mathrm{~g}$ and $\mathrm{b}$ (at fault strands $8-11$ ) have a stratigraphic correlation rating of 1 with the type locale of Event 5, at fault 15 . 
Additional evidence for event 5 consists of a fissure (f) between faults 21 and 23 at $22 \mathrm{~m}$ capped by the orange horizon on the east wall (Figure 7 ). Both the fissure and the orange horizon have been offset in a younger earthquake on fault 22. The quality rating for this indicator is only 1 because (a) faults 21 and 23, which bound the proposed fissure fill, have re-ruptured in one or more events (i.e., there are no upward fault terminations at this level), and (b) the proposed fissure fill could instead be a faulted section of the massive material that underlies the orange horizon farther south. Correlation of orange horizon across faults $16-18$ is uncertain. If the solid orange horizon south of faults $16-18$ correlates with dashed orange horizon to south, then fissure (f) might represent an older event than the one at $\mathrm{d} 1$ (but still younger than event 6). As a second alternative, if the solid orange contact south of fault 18 correlates with the dotted orange horizon north of fault 16 , then fissure (f) would correlate with event 6 . The preferred correlation remains shown by the position of the solid orange line in Figure 1, but due to the uncertainty in this correlation, this indicator is given a stratigraphic correlation rating of 1 .

At $22.5 \mathrm{~m}$ on the east wall (Figure 7) a subtle fold axis is marked with a vertical dashed line labeled "19". This fold axis has greater deformation below the orange horizon than above, providing further support for event 5 (quality rating 1). This indicator also receives a stratigraphic correlation rating of 1 because of the uncertainty of the correlation of the orange horizon across faults 16-18, as described above. 
On the west wall, event 5 is represented by fault strands 27 and 32 at locations (a) and (z) (Figure 8). Fault strand 27 at $19 \mathrm{~m}$, appears to offset the orange horizon by $2 \mathrm{~cm}$ at location (a) and is capped by the first ledge above orange (quality rating 1) (Figure 8 ). Possible fault 32 with very minor offset (if any) is capped by the orange horizon at $21.5 \mathrm{~m}$ at location ( $\mathrm{z}$ ) (quality rating 0 ). Fault strands 27 and 32 have a stratigraphic correlation rating of 1 and 0 respectively. Correlation of the orange horizon is good between these two indicators on the west wall, and fissure (f) and fold axis (c) on the east wall. However, as noted above, correlation of the orange horizon across faults 16-18 on east wall is uncertain, leading to a stratigraphic correlation of 1.

\section{Event 6}

Event 6 is represented by a possible fissure (d) at $24 \mathrm{~m}$ on the east wall (quality rating 4), which is capped by the purple horizon (Figure 7). Fault strand 14 , forming the south wall of the fissure, terminates a few centimeters below the purple layer. Fault strand 13, on the north side of the fissure ruptured again in a younger event. This is the type locale for event six, but uncertainty in correlation of the orange horizon across faults $12-13$ and 16-18 allows that this indicator could be associated with event 5 , although that is not the preferred interpretation. This uncertainty gives this indicator a stratigraphic correlation of 3 , even though this is the type locale. If this indicator were to be associated with event 5 instead of event 6 , then there would need an added event, 4.5, to explain indicator $\mathrm{d} 1$. 


\section{Event 7}

Event 7 is represented by an angular unconformity capped by the yellowgreen horizon at location (k) between fault strands 8 and 9 at $25 \mathrm{~m}$ on the east wall (Figure 7). Layers below the yellow-green horizon are tilted substantially, and the yellow-green horizon is not tilted (quality rating 3 ). The tilted block is bounded by faults 8 and 9 , but these faults also re-ruptured in event 5 . The angular unconformity clearly underlies the purple horizon, so this cannot be part of event 6 . This indicator is the type locale and is given a stratigraphic correlation of 5.

\section{Event 8}

Event 8 is represented by fault strand 57 , which has moderate vertical separation $(8 \mathrm{~cm})$ and has a distinct upward termination at location $(\mathrm{m})$ near the top of the deep slot at $20.5 \mathrm{~m}$ (Figure 9) on the east wall (quality rating 3 ). The scarp is buried by the base of a silty layer (yellow-orange horizon), which appears to thicken to the south, as a result of the accommodation space generated by vertical separation across the fault (Figure11). However, the silty layer is just below the bench level, so it is unclear whether the top of this layer is preserved within the deep slot has or been cut off by the bench. The fault does appear to be truncated by the yellow-orange horizon, but this horizon is cut out by the bench only $4 \mathrm{~cm}$ north of the fault. Therefore, it cannot be ruled out that fault strand 57 could have gone around the north edge of the yellow-orange horizon and have extended higher in the section. Nonetheless, there is no fault visible in either phase I or phase II of the upper tier, above this fault. This is the 
type locale for event 8 . This event is clearly younger than event 9 . There is a small chance it could be the same as event 7 , but the preferred correlation of the yellow-orange horizon across several faults and bench suggests this horizon is at least $40 \mathrm{~cm}$ below the event 7 horizon. Due to this uncertainty, this indicator is given a stratigraphic correlation of 3 instead of 5 for a type locale.

\section{Event 9}

Event 9 is represented by five lines of evidence, each with a quality rating of 2. Of these, the indicator selected as the type locale is an angular unconformity ( $1, p 2)$, at meter 21-21.5 on the east wall deep slot, where gently tilted layers are capped by less tilted layers above the dark blue horizon. The unconformity has been offset by younger faulting (Figure 9).

An angular unconformity is seen at the same approximate stratigraphic level $(21 \mathrm{~m})$ on the west wall (location $\mathrm{p})$, where several short contacts are gently tilted beneath a horizon, which is not tilted (Figure 10). The untilted horizon has been colored dark blue to illustrate the inferred correlation of these angular unconformities. The tilted beds are within a fault bounded block, but the folding amplitude is small, and the layers are discontinuous due to bioturbation. Therefore, the quality ranking for this indicator is only 2 .

Immediately to the south of angular unconformity (p), fault strands 65 and 66 are terminate upward distinctly at the base of a scoured channel (quality rating 2). It is inferreed that this channel scoured into the event 9 horizon south of 20.3 $\mathrm{m}$, so the part of the base of the channel south of $20.3 \mathrm{~m}$ forms the event 9 horizon and is thus colored dark blue. 
At $19.0-19.5 \mathrm{~m}$ on the west wall, a possible filled fissure (a) and fault strand 62 are capped by a contact at the approximate stratigraphic level of the scoured channel, so this fissure is also inferred to have formed during event 9 and the contact that overlies it is colored dark blue. Although fissures generally earn a quality ranking of 4 , this one is downgraded to a quality ranking of 2 because the capping layer is discontinuous due to bioturbation. Fault strand 62 is on the southern edge of the possible filled fissure. Because this indicator is at the same approximate depth as the angular unconformity, on the east wall, it is given a stratigraphic correlation rating of 3 .

A final line of evidence is a possible fissure (b3) at $18 \mathrm{~m}$ on the east wall. This event indicator is questionable because after moving the hydraulic shore it appeared that this potential fissure could be a bioturbated zone (Figure 9). Nonetheless, the original trench excavated at this location in 1990 showed faulting at this meter mark in the trench (Figure A1 in Appendix A). Due to the uncertainties with this indicator it is given a quality rating of 2 . The potential fissure and fault strand 59, which forms the south wall of the fissure, are capped at a level that could potentially correlate with the angular unconformity at the type locale for event 9 on the east wall. Therefore, this indicator is assigned a stratigraphic correlation rating of 2 .

\section{Event 10}

Event 10 is represented by a possible filled fissure $(y)$ and a possible upward termination of fault strand 70 on the west wall at $21 \mathrm{~m}$ (Figure 10). The quality rating for this indicator is only 2 because the capping layer does not 
extend very far beyond the fissure, and because the stratigraphy above the upward termination of fault 70 has been destroyed by bioturbation, so it is uncertain whether fault 70 extended higher or not. This indicator is the type locale for event 10 and is given a stratigraphic correlation of 4 . It is given a rating of 4 because it is at a lower stratigraphic level than event 9 , and is higher than event 11 , near the base of the trench, so this is most likely a separate event.

\section{Older events}

There is potential for one or more older events where minor faults offset the lake beds near the base of the trench at $23-24 \mathrm{~m}$ on the east wall and at 22$23 \mathrm{~m}$ on the west wall (Figure 9). These faults are not visible within the thick, massive sediments that overlie the lake beds, so they may have formed in one or more events that predate event 10 . However, there is no stratigraphic contact that clearly defines the upward termination of these faults, so it is possible that they extend upward into the massive material and thus could have formed during any of the younger events that have been discussed previously. These indicators are given a quality rating of 0 because it is unclear whether they formed in events that are distinct from those have been described above. These indicators also cannot be correlated with any other event horizon and are not given a stratigraphic correlation rating due to the lack of stratigraphy.

There is also a faulting event on a moderately south-dipping fault with a likely thrust component of slip, north of the bedrock sliver. This event indicator is in the deep slot at $27-28 \mathrm{~m}$ on the east wall (Figure 11). A fine silty sand layer is buried by dipping beds of a colluvial wedge that likely was derived from a scarp 
that formed in response to slip on fault strands $43-45$, between $26-27$ m. Fault strand 43 appears to terminate upward at the base the colluvial wedge. Faults strand 44 and 45 may continue upward into the upper tier, where they may be expressed as faults 1-3. This event, north of the bedrock sliver, may or may not correlate with any of the events that have been described south of the bedrock sliver. 


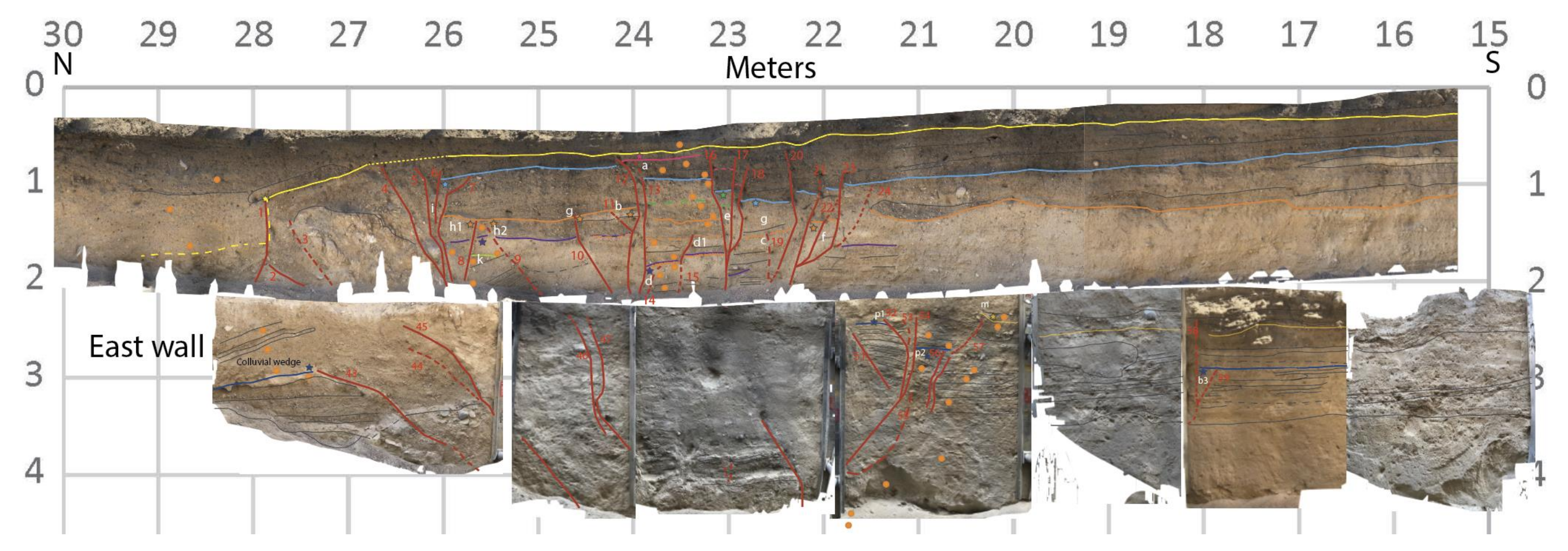

Figure 5. Photomosaic of the east wall upper tier showing the event 1 (yellow horizon), event 2 (pink horizon) event 3 (light blue horizon), event 4 (green horizon), event 5 (orange horizon), event 6 (purple horizon), event 7 (yellow-green horizon), event 8 (dark yellow horizon), and event 9 (dark blue horizon) horizons. In the upper tier, the extent of the yellow, blue, and orange horizons can be seen. Grid is one meter with no vertical exaggeration. Filled orange circles mark locations of luminescence samples that were collected. 


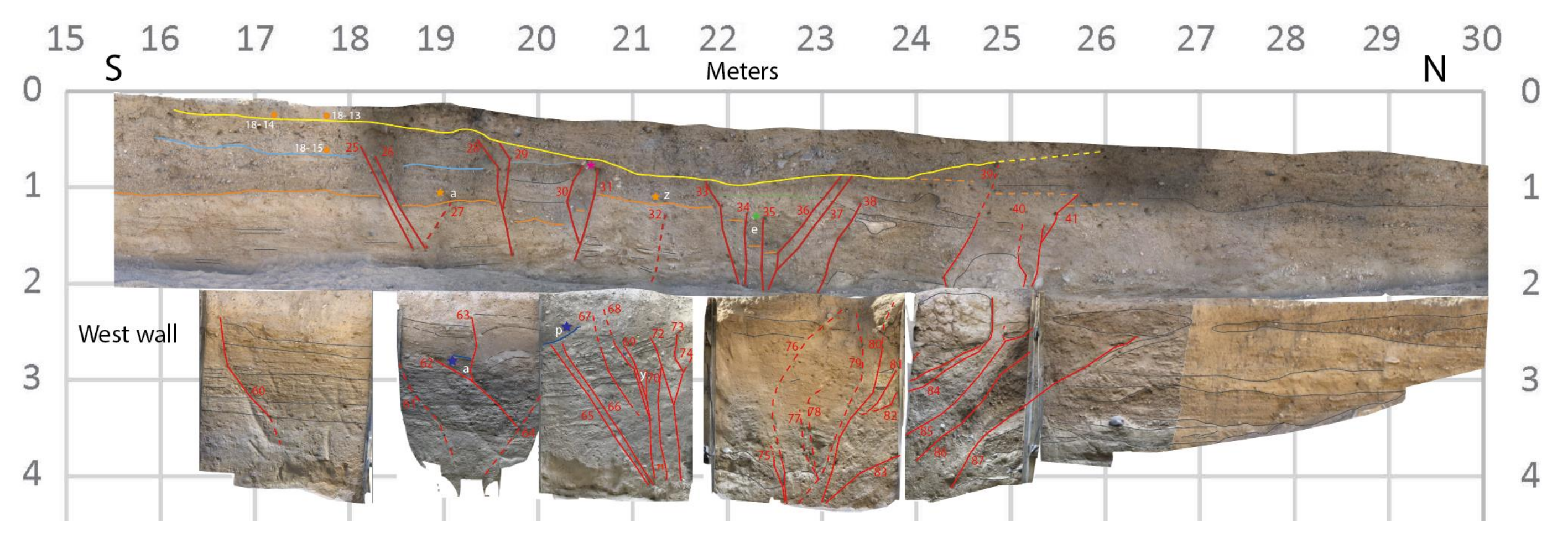

Figure 6. Photomosaic of the west wall showing an overview of the main fault zone of the upper tier and the deep slot. Yellow, light blue, green, orange and dark blue lines mark the event 1 , event 3 , event 4 , event 5 and event 9 horizons, respectively. 

28
27
26
25
24
23
22
Meters
$\mathrm{S}$

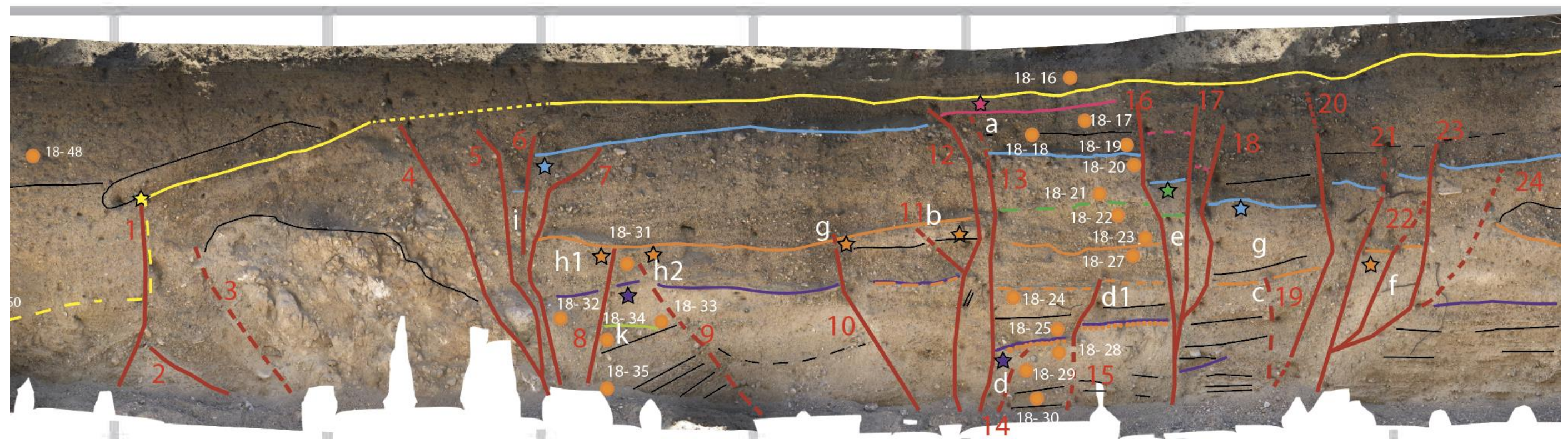

Figure 7. Enlarged view of the fault zone (21-28 m) within the upper tier on the east wall showing evidence for events 1-7. Colored lines mark earthquake horizons and stars mark locations of evidence for events. Event 1: yellow; Event 2: pink; event 3: light blue; event 4: green; event 5: orange; event 6: purple; event 7: yellow green. Refer to text for alternate interpretations of event 5 horizon, shown by dashed and dotted orange lines. No vertical exaggeration. Dashed yellow line near fault 1 is marking the 25 -cm-thick pebble layer that was folded. 


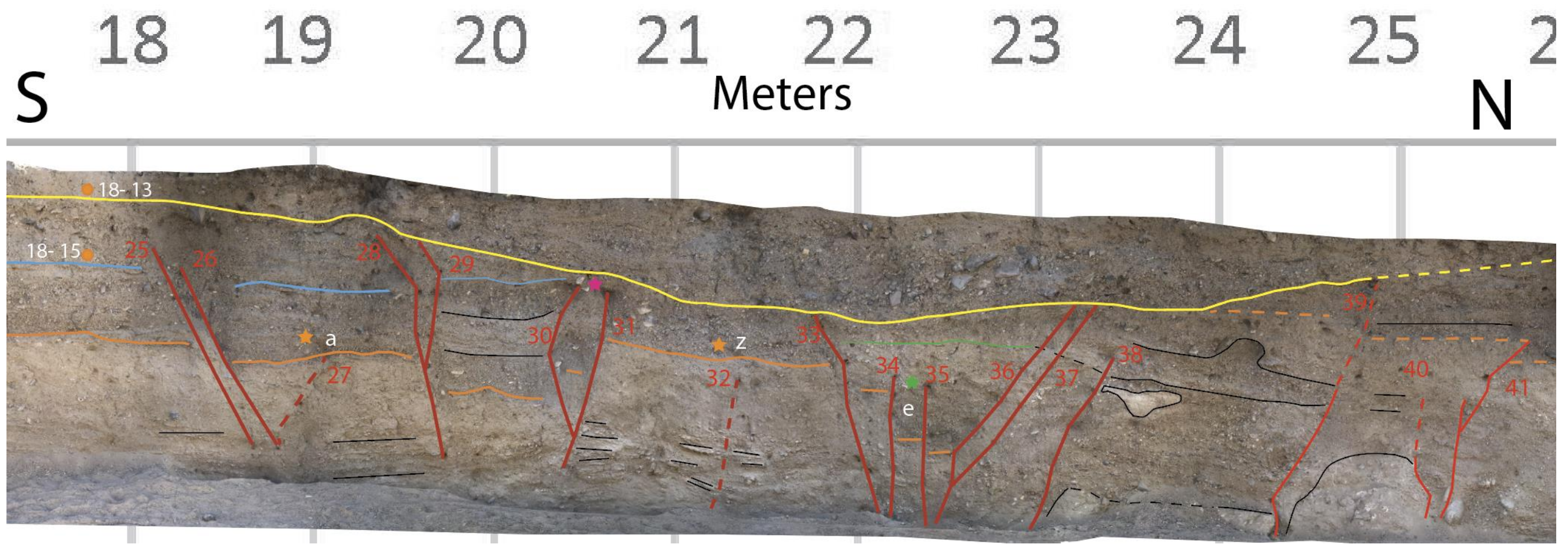

Figure 8. Enlarged view of the fault zone (17-23 m) within the upper tier on the west wall showing evidence for events 1,4 , and 5 at locations of yellow, green and orange stars. No vertical exaggeration. 

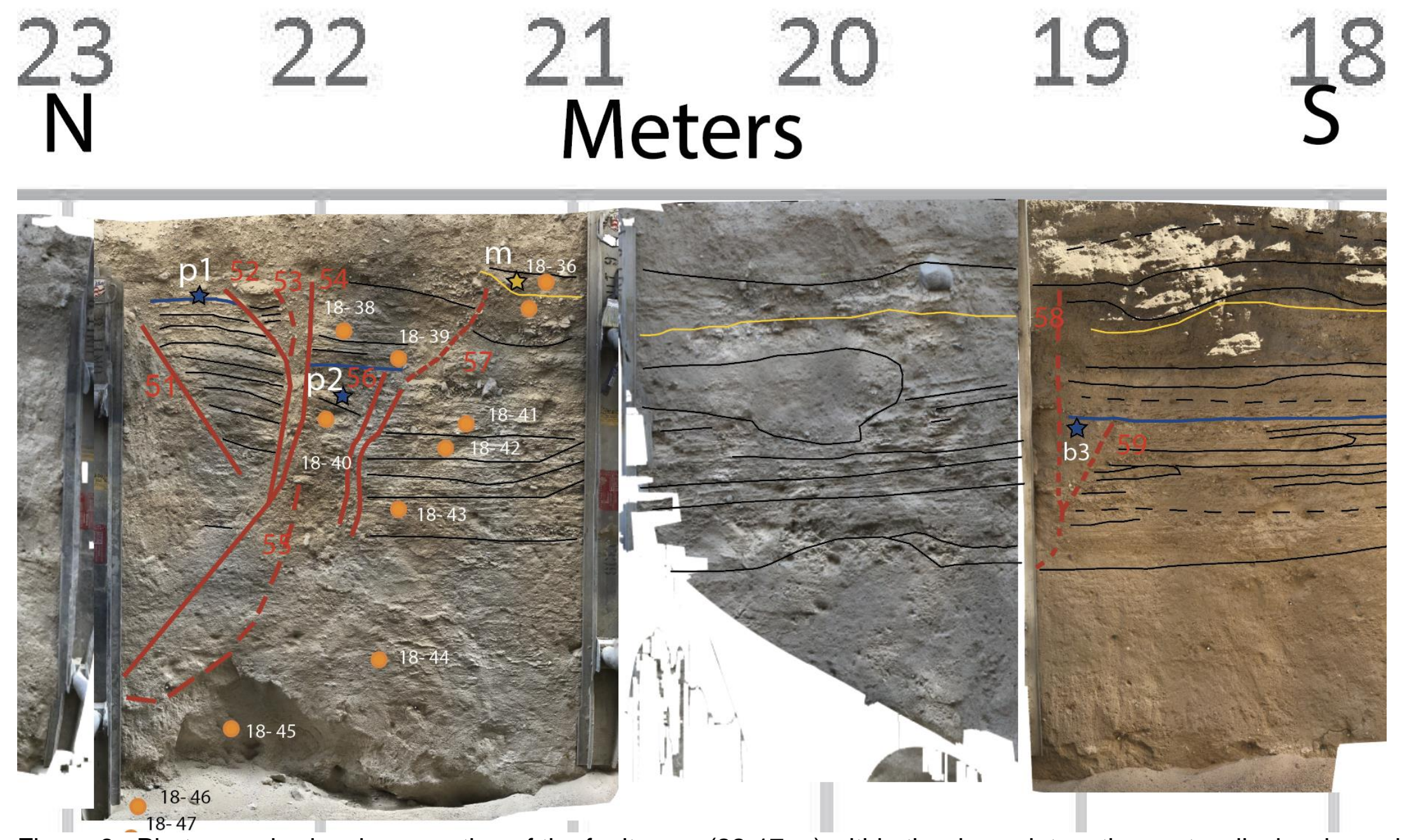

Figure 9. Photomosaic showing a portion of the fault zone (22-17 m) within the deep slot on the east wall, showing evidence for events 8 (dark yellow horizon and star) and 9 (dark blue horizon and stars). 


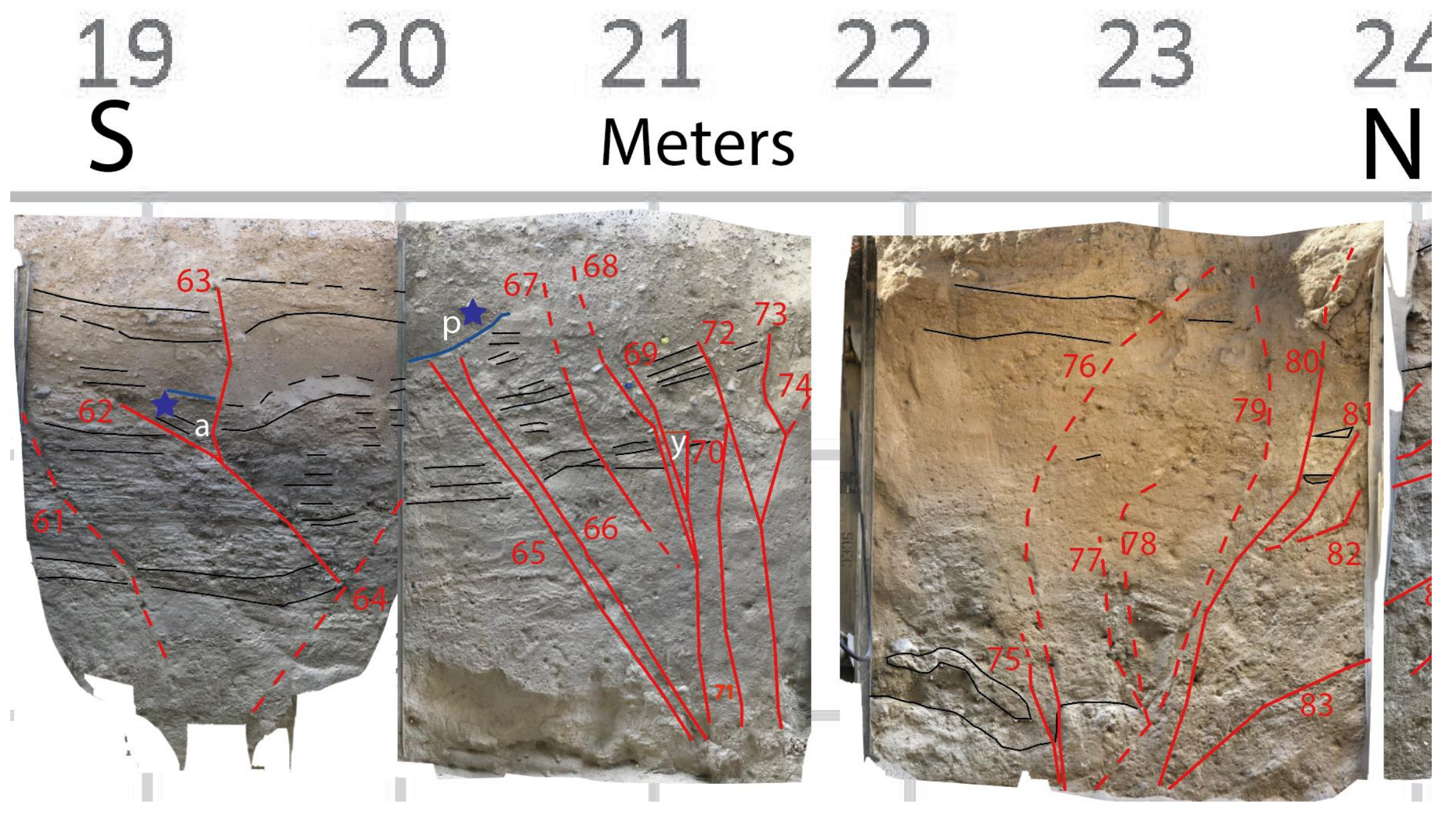

Figure 10. Photomosaic showing a portion of the fault zone (19-24 $\mathrm{m}$ ) within the deep slot on the west wall showing evidence for event 9 (dark blue horizon). 


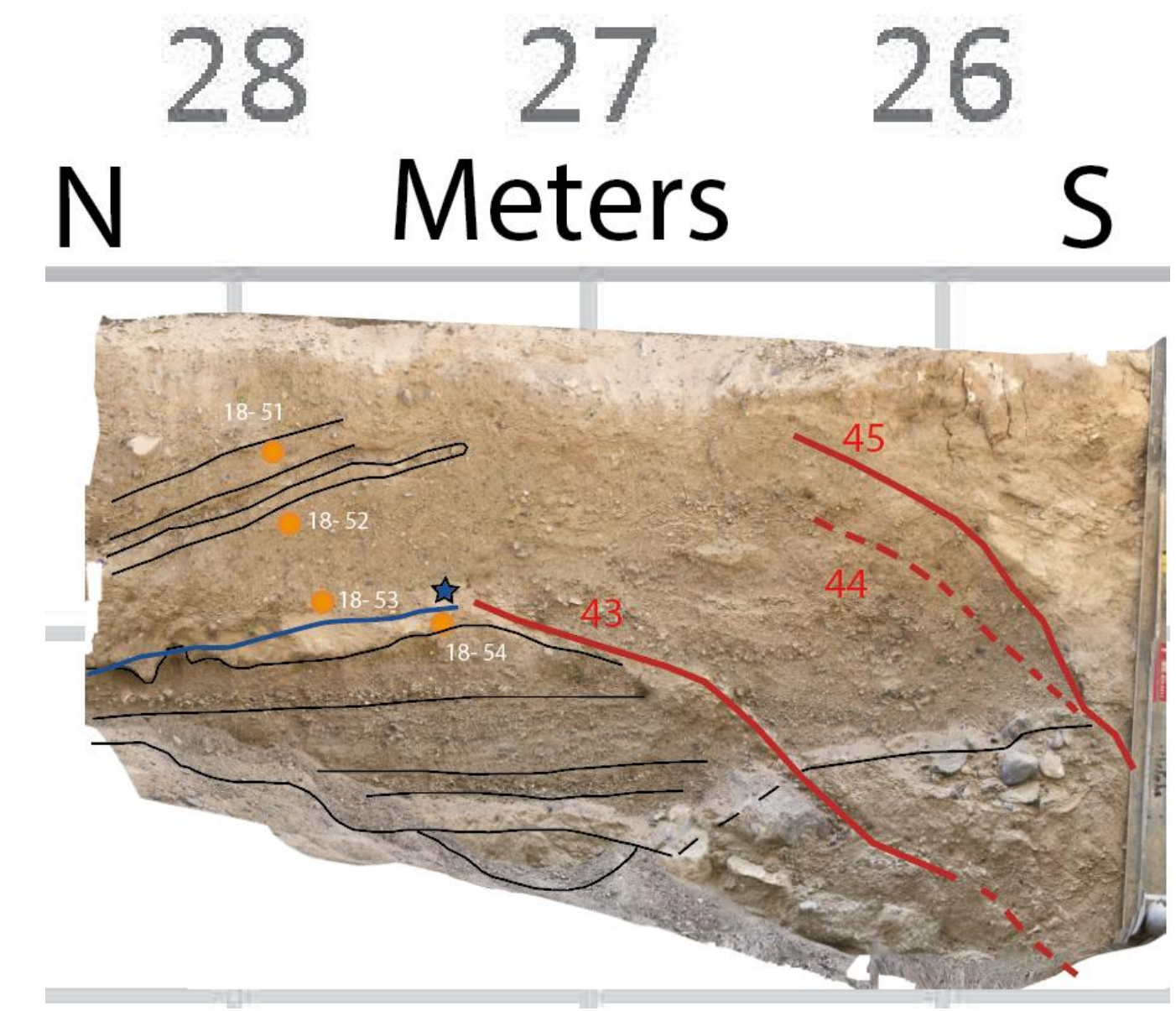

Figure 11. Older thrust event (dark blue horizon) showing colluvial wedge deposited on top of a flat-lying silty sand layer within the deep slot on the east wall. 
Table 3. Criteria for Assigning Quality

Quality Rank 0

- Fault tip where upper termination not distinct due to unclear stratigraphy, and this results in uncertainty as to in which event this fault slipped, with no preferred event horizon among the possibilities.

- Or, upward termination may be distinct, but it remains unclear which event the fault is associated with, because the fault terminates upward at a scoured contact that erodes through one or more event horizons.

Quality Rank 1

- Fault with minor offset $(<5 \mathrm{~cm})$, even if the upward termination is distinct.

- Or, fault with moderate offset but indistinct upward termination, allowing multiple interpretations for the event horizon during which this fault slipped. Nonetheless, there is reason to prefer one of the possible interpretations.

- Or, Minor and gradual thickness changes that could simply reflect depositional gradients rather than filling of earthquake produced depression. - Or, folding amplitude small, and thickness change above horizon of folding is moderate, but stratigraphic location of the lowest unfolded layer is indistinct enough to allow for multiple interpretations for the stratigraphic event horizon during which this folding occurred. Nonetheless, there is reason to prefer one of the possible interpretations.

- Or, Possible fissure which could alternatively be interpreted as a throughgoing massive layer disrupted by faults.

Quality Rank 2

- Fault with moderate offset $(\geq 5 \mathrm{~cm})$, and indistinct upward termination, but the indicator can still be clearly associated with one event horizon.

- Or, Folding amplitude small, and thickness change above horizon of folding is moderate

Quality Rank 3

- Fault tip with distinct upward termination, moderate offset $(\geq 5 \mathrm{~cm})$.

- Or, Folding and thickness changes in layers above folding horizon that are substantial, but folding horizon has no clearly causative fault and (or) the horizon of folding is difficult to discern.

- Or, Possible fissure for which the fill material does not clearly postdate the inferred event horizon, and both walls of the fissure are faults that have reruptured in a younger event.

Quality Rank 4 
- $\quad$ Fault tip associated with colluvial wedge or other layer thickness changes.

- Or, Possible fissures for which the fill material does not clearly postdate the inferred event horizon, but at least one wall of the fissure is a fault with a distinct upward termination, which has not re-ruptured in a younger event. - $\quad$ Or, Broad warping and large thickness changes in layer above folding horizon indicate rapid filling of

depression, closely related to fault that moved to provide accommodation space

Quality Rank 5

. $\quad$ Fissures that are clearly filled with the material that postdates inferred event horizon.

- $\quad$ Or, Folding and growth strata in which it is clear that the topography was rapidly filled by a single sedimentation event and has a casual fault modified from Scharer et al., (2017) and Castillo (2019). 
Table 4. Criteria for Assigning Stratigraphic Correlation Rankings

\section{Stratigraphic Correlation Ranking N/A:}

No correlation rating is given in cases in which the quality rating is so low (zero) that it is unclear with which event an indicator may correlate.

Stratigraphic Correlation Ranking 0:

Correlation is so intractable that the event indicator is not assigned to any particular event. This is only used for one event indicator on the north side of the bedrock sliver.

Stratigraphic Correlation Ranking 1:

Stratigraphic correlation of one or more event horizons is uncertain enough to create ambiguity as to with which event this indicator should be associated. Nonetheless, the indicator is assigned to a specific event horizon in Table S1 for accounting.

Stratigraphic Correlation Ranking 2:

The stratigraphic level of the indicator cannot be physically traced all the way to the type locale, because it crosses more than one fault, bench or area of poor stratigraphy, leading to a relatively high level of uncertainty, including the possibility that the indicator could correlate with an event other than the proposed event.

Stratigraphic Correlation Ranking 3:

(a) The stratigraphic level of the indicator cannot be physically traced all the way to the type locale, because it crosses a fault, a bench or an area of poor stratigraphy. The correlation of strata is somewhat uncertain, but correlation with the proposed event is much more likely than correlation with any other recognized event. This rating may be applied to an indicator on the opposite wall from type locale for the event, as long as it is not far above or below one of the three layers that have been correlated between the walls (the yellow, blue and orange horizons).

Or (b) The stratigraphic level of the indicator cannot be physically traced all the way to the type locale, because it crosses a fault, a bench or an area of poor stratigraphy, but the correlation of strata is fairly certain, but is on the opposite wall from the type locale and is farther from one of the three layers that can be correlated between walls.

Or (c), the indicator is the type locale, but could potentially belong instead to a different event, given uncertainties in correlation. 
Stratigraphic Correlation Ranking 4:

The stratigraphic level of the indicator cannot be physically traced all the way to the type locale, because it crosses a fault, a bench or an area of poor stratigraphy, but the correlation of strata is fairly certain. This rating may also be applied to an indicator on the opposite wall from type locale for the event, as long as it is not far above or below one of the three layers that have been correlated between the walls (the yellow, blue and orange contacts).

Stratigraphic Correlation Ranking 5:

The stratigraphic level of the indicator can be physically traced all the way to the type locale, with no uncertainty in correlation of strata across any faults located between the indicator and type locale. This can only be true for indicators that are on the same wall as the type locale for event. (Modified from Castillo, 2019). 


\section{CHAPTER FOUR}

\section{DISCUSSION}

IRSL ages have been received for 14 samples (Table 5, Figure 12).

OxCal (Ramsey, 2009) was used to refine the age estimates using a Bayesian approach to reweight the probability density functions (pdfs) for each samples age and to compute pdfs for the age of each event (Table 6 and Figure 13). The ages for samples were consistently older with stratigraphic depth, except for a few minor age inversions for which the sample age error bars overlap. Table 5 gives ages in years before present (BP), by which means years before 2018, as well as in years of the Common Era (CE) or Before Common Era (BCE). In the text that follows, ages are reported in year $\mathrm{CE} / \mathrm{BCE}$, for ease of comparison with dated prehistoric earthquakes at other sites.

The one sample (18-17) that was collected between events 1 and 2 has not yet been dated. Therefore, at this time events 1 and 2 occurred between $1950 \pm 20$ years CE (sample 18-16) and $1190 \pm 80$ years CE (sample 18-18), or between $\sim 1110-1970 \mathrm{CE}$. The OxCal model estimates the ages of events 1 and 2 to be 1320-1970 CE and 1110-1820 CE, respectively. Historical data indicate that the most recent event probably occurred before 1903 CE (Hanks et al., 1975; McGill, 1992), so the age constraints on event 1 is best reported as 1322 1903 CE. Sample 18-20, taken below the event 3 horizon, has an intrinsically unstable age distribution and could represent a range of ages between c. 2000 
BCE to 400 CE yrs ago. Event 3 thus occurred sometime between 400 and 1270 $\mathrm{CE}$, and the OxCal model estimates the age as $1110 \mathrm{BCE}-1170 \mathrm{CE}$. Event 4 occurred between the ages of samples $18-20$ and $18-23$, so its age is between $1850 \mathrm{BCE}$ and $420 \mathrm{CE}$, with the OxCal estimate being 960-1830 BCE. Event 5 is bracketed by samples $18-23$ and $18-27$ yielding an age between $1410-2480$ years BCE, with an OxCal estimate of 1500-2490 BCE. Event 6 is bracketed by samples 18-25 and 18-28 and occurred between 3230-5230 BCE, with an OxCal estimate of 2270-4690 BCE. Samples above and below event 7 were not dated and no age ranges are available for this event. Event 8 is bracketed by samples 18-36 and 18-37 which put the age of event 8 at 5030-5440 BCE, with an OxCal estimate of 4700-5570 BCE. Event 9 was bracketed by samples 18-39 and 1840 which put the age of event 9 at 5480-5930 BCE, with an OxCal estimate of 5250-6180 BCE. Sample 18-47 was taken at the base of the trench in a layer of well-sorted sand, which was interpreted as being from the last high of Searles Lake and was dated at $7980 \pm 490$ years BCE, which is consistent with previously reported ages for the most recent high stand (Benson et al., 1990). With the age of sample 18-47, a record exists of almost the entire Holocene epoch within the trench.

When comparing events at the CCW trench to the other paleoseismic sites on the central GF several observations can be made (Figure 3). The two most recent events at CCW occurred within a broad interval between 1110-1903 C.E. The MRE at both the EPP site (1450-1640 CE; Dawson et al., 2003) to the 
west and the Echo Playa site (1615-1820 CE.; Kemp et al., 2016) to the east occurred within this interval (Figure 3). The age constraints for the MREs for all three of these sites overlap and could have occurred during the same seismic event. It appears that there were two events at CCW during the same time period that only one event occurred at EPP and Echo Playa (Figure 3). It is also worth mentioning that the ages for MREs at the two paleoseismic sites on the western Garlock Fault (TL and CW) overlap with the ages for the MRE from the three sites on the central Garlock Fault (EPP, CCW and Echo Playa), suggesting that the MRE may have ruptured both the central and western Garlock Faults simultaneously or within a period of a few decades of each other.

The third event at CCW occurred within a broad range between $1110 \mathrm{BCE}$ and $1170 \mathrm{CE}$ (using the OxCal model age for event 3). Both the second and third events at EPP (675-950 CE, 250-475 CE; Dawson et al., 2003) and at Echo Playa (470-730 CE, 40-150 CE.; Kemp et al., 2016) occurred during this interval. For both the second and third events at EPP and Echo Playa the dates for each event overlap between these two sites and could represent the same earthquake at both sites. Thus, event 3 at CCW could correlate with either event 2 or event 3 at EPP and Echo Playa. It is also possible that events 2 and 3 at EPP and Echo Playa represent up to four separate seismic events. At CCW there is only evidence for one event during the time period in which events 2 and 3 occurred at EPP and Echo Playa, but it is possible that an additional event occurred at CCW and was undetectable in the trench. For example, the blue horizon at 
CCW could represent two events with either no deposition between them, or erosion of any sediment that was deposited between them prior to event 3 at CCW.

Event 4 at CCW occurred between 1830-960 BCE, and event 5 at CCW occurred between 2490-1510 BCE. Both events overlap with the age of event 4 at Echo Playa (275-1950 BCE). There was no evidence for any faulting events at EPP during this period.

Event 6 at CCW occurred between 4690-2270 BCE, which overlaps by 20 years with EPP event 6 that occurred between 5300-4670 BCE, but it likely that these may be two separate events.

Evidence found at the CCW paleoseismic site does not perfectly match the evidence found at EPP or Echo Playa. Both the CCW and Echo Playa sites have evidence for only 3 earthquakes during the cluster of four earthquakes seen at EPP within the past $2 \mathrm{ka}$. Furthermore, the dates of the three earthquakes at CCW and Echo Playa do not all match: only one event was documented at Echo Playa during the period in which the two most recent events occurred at CCW, and only one event occurred at CCW (event 3 ) during the period in which events 2 and 3 occurred at Echo Playa. In addition, both CCW and Echo Playa record faulting events that occurred within the seismic hiatus between 2-5 ka at EPP. At least two events at CCW (Events 4 and 5) and at least one event at Echo Playa (Event 4) occurred within the seismic lull at EPP. 
On July 4, 2019 a M6.4 earthquake occurred on a northeast-striking fault north of the Garlock Fault, near the town of Ridgecrest (U.S. Geological Survey, 2019a). This was followed by a M7.1 earthquake on July 5, with surface rupture extending northwest and southeast of the location of the July 4 event with up to $4.2 \mathrm{~m}$ of right-lateral slip (U.S. Geological Survey, 2019b; U.S. Geological Survey, 2019c). The surface rupture from the M7.1 event extended southeastward to within a few km from the Garlock Fault, near the location of the CCW trench (Geotechnical Extreme Event Reconnaissance Association, 2019; Ross et al., 2019), as did the aftershocks (Stein et al., 2019). Aftershocks were exclusively concentrated to the north of the Garlock Fault, which indicates that it is a major boundary. The Ridgecrest earthquakes caused an increase in Coulomb stress along a $30 \mathrm{~km}$ section extending westward from the CCW trench (Stein et al., 2019). InSAR data indicated that the Ridgecrest earthquakes triggered shallow creep along a $\sim 30 \mathrm{~km}$ section of the Garlock Fault near and east of the CCW trench (Ross et al., 2019). En echelon cracks were observed along the Garlock Fault near the CCW trench, but creepmeters that were installed within two weeks after the earthquakes recorded only $<50 \mu \mathrm{m}$ within 2 weeks to 2 months after the quakes (Bilham and Castillo, 2019).

Considerable media attention was given to the occurrence of "unprecedented" minor slip triggered on the Garlock Fault by the Ridgecrest earthquakes (Associate Press, 2019). However, it is not uncommon for an earthquake to trigger slip on other nearby faults (e.g., Williams et al., 1988). 
The Ridgecrest earthquake sequence provides a new perspective on the Garlock Fault. Given that the surface rupture and aftershocks of the M7.1 earthquake extended to within a few $\mathrm{km}$ of the Garlock Fault near the CCW trench site, it is possible that the end points of past earthquake ruptures on the Garlock Fault may have been influenced by earthquakes similar to the 2019 Ridgecrest earthquake sequence, or by earthquakes on the Blackwater fault which projects northward toward the Garlock Fault near the CCW trench. In the case of earthquakes like the 2019 Ridgecrest sequence, Coulomb stresses on the Garlock Fault would be increased near and west of the CCW trench (Stein et al., 2019), potentially triggering an earthquake that might rupture the El Paso Peaks site, with or without rupture at the CCW site. Prehistoric earthquakes on the Blackwater fault would have the opposite effect, increasing Coulomb stress on the portion of the Garlock Fault near and east of the CCW trench site, potentially triggering an earthquake that would rupture the Garlock Fault at Echo Playa, with or without rupture at CCW. This interaction of northwest striking faults of the Eastern California Shear Zone (ECSZ) with the Garlock Fault is one potential mechanism for explaining differences in earthquake histories between El Paso Peaks, CCW and Echo Playa. However, this mechanism may be a relatively minor influence on the Garlock Fault because fault slip rates in the ECSZ (Oskin et al., 2008) are generally slower and earthquake recurrence intervals longer (Rubin and Sieh, 1997). In fact, if the recurrence interval for earthquakes like the 2019 Ridgecrest earthquake sequence is comparable to the 
$\sim 9$ ka recurrence interval for the Emerson fault in the ECSZ, then it is possible that the only other event like the Ridgecrest sequence may have occurred within the entire Holocene time period that is recorded in the CCW trench.

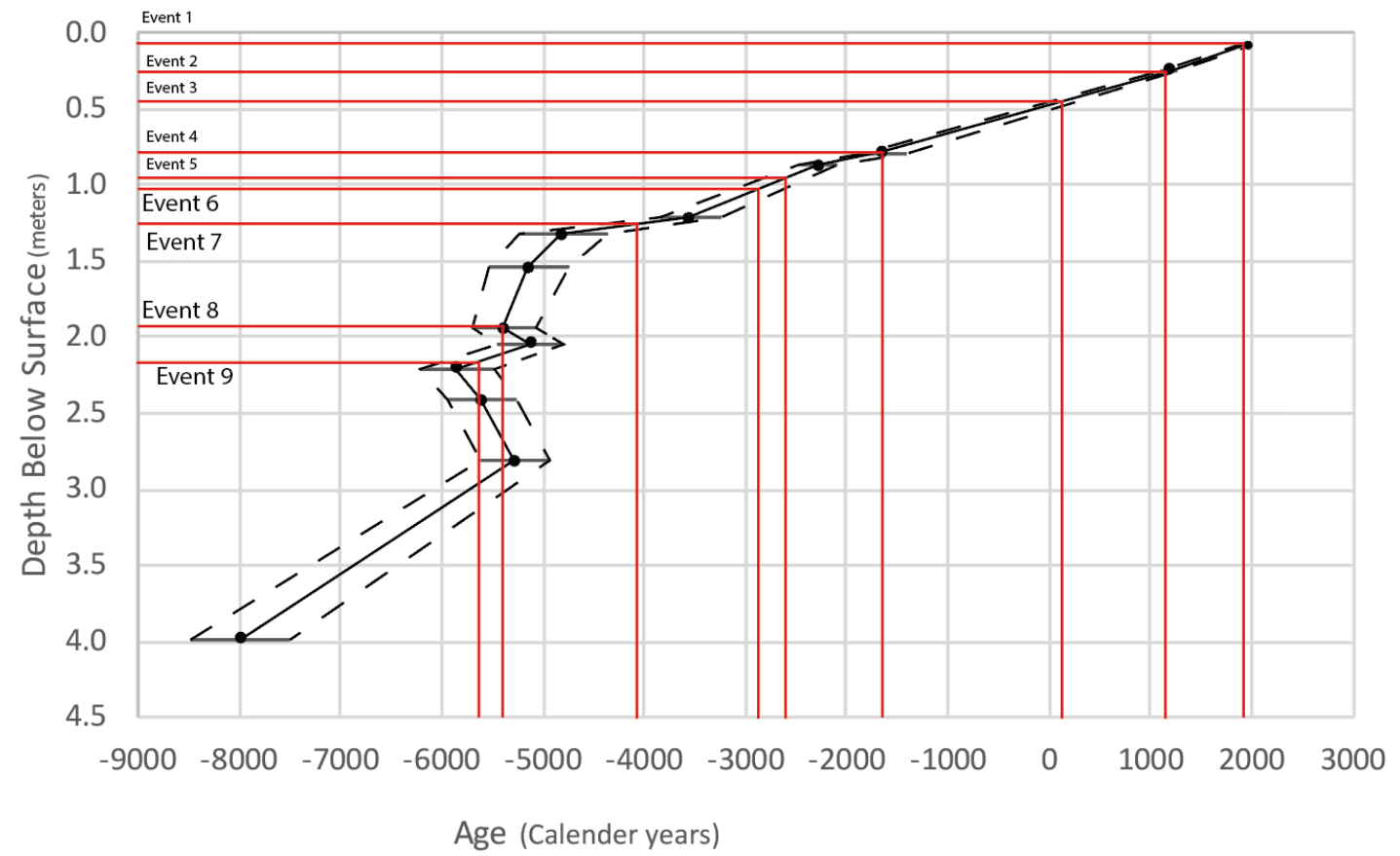

Figure 12. Age versus stratigraphic depth of IRSL samples. Horizontal red lines indicate the approximate stratigraphic depth of event horizons. Vertical red lines represent the interpolated ages of events based on their stratigraphic depth between dated samples. 
Table 5. Table of IRSL Samples with their Depth from Ground Surface and Age

\begin{tabular}{|c|c|c|c|}
\hline $\begin{array}{l}\text { Sample } \\
\text { Number }\end{array}$ & $\begin{array}{l}\text { Age (years } \\
\text { before 2018) }\end{array}$ & "Age (CE/BCE) & $\begin{array}{l}\text { Depth } \\
\text { (meters) }\end{array}$ \\
\hline 18-16 & $70 \pm 20$ & 1930-1970 CE & 0.068 \\
\hline $18-18$ & $830 \pm 80$ & 1110-1270 CE & 0.242 \\
\hline $18-20$ & $3210 \pm 190$ & $1380-1000$ BCE & 0.447 \\
\hline $18-23$ & $3650 \pm 220$ & 1850-1410 BCE & 0.785 \\
\hline $18-27$ & $4300 \pm 200$ & 2480-2080 BCE & 0.870 \\
\hline $18-25$ & $5560 \pm 310$ & 3850-3230 BCE & 1.215 \\
\hline $18-28$ & $6820 \pm 430$ & $5230-4370$ BCE & 1.325 \\
\hline $18-30$ & $7160 \pm 390$ & $5530-4750$ BCE & 1.545 \\
\hline $18-36$ & $7400 \pm 350$ & 5730-5030 BCE & 1.939 \\
\hline $18-37$ & $7140 \pm 320$ & $5440-4800$ BCE & 2.037 \\
\hline $18-39$ & $7860 \pm 360$ & $6200-5480$ BCE & 2.203 \\
\hline $18-40$ & $7620 \pm 330$ & 5930-5270 BCE & 2.415 \\
\hline $18-43$ & $7300 \pm 340$ & 5620-4940 BCE & 2.809 \\
\hline $18-47$ & $10000 \pm 490$ & 8470-7490 BCE & 3.988 \\
\hline
\end{tabular}


Table 6. OxCAL Results Showing Unmodeled Sample Ages, and Modeled Event Ages

\begin{tabular}{|c|c|c|c|c|c|c|c|}
\hline \multicolumn{2}{|c|}{$\begin{array}{l}\text { Unmodeled }(\mathrm{BCE} / \mathrm{CE}) \\
\text { From } / \text { to } \\
2-\sigma \text { range }\end{array}$} & \multicolumn{3}{|c|}{$\begin{array}{l}\text { Modeled (BCE/CE) } \\
\text { From/to } \\
\text { 2- } \sigma \text { range }\end{array}$} & \multicolumn{3}{|c|}{$\begin{array}{l}\text { Modeled Age b2018 } \\
\text { Mean Age } \\
2-\sigma \text { range }\end{array}$} \\
\hline \multicolumn{8}{|c|}{ Boundary Surface } \\
\hline $\begin{array}{l}\text { C_Date } \\
18-16\end{array}$ & 1908 & 1988 & 1907 & 1988 & 111 & 30 & \\
\hline E1 & & & 1322 & 1966 & 696 & 52 & 374 \\
\hline E2 & & & 1107 & 1820 & 911 & 198 & 554.5 \\
\hline $\begin{array}{l}\text { C_Date } \\
18-18\end{array}$ & 1028 & 1348 & 1016 & 1332 & 1002 & 686 & \\
\hline E3 & & & -1107 & 1167 & 3125 & 851 & 1988 \\
\hline $\begin{array}{l}\text { C_Date } \\
18-20\end{array}$ & -1574 & -814 & -1469 & -774 & 3487 & 2792 & \\
\hline E4 & & & -1833 & -959 & 3851 & 2977 & 3414 \\
\hline $\begin{array}{l}\text { C_Date } \\
18-23\end{array}$ & -2074 & -1194 & -2033 & -1298 & 4051 & 3316 & \\
\hline E5 & & & -2490 & -1505 & 4508 & 3523 & 015.5 \\
\hline $\begin{array}{l}\text { C_Date } \\
18-27\end{array}$ & -2684 & -1884 & -2715 & -1968 & 4733 & 3986 & \\
\hline E6 & & & -4692 & -2270 & 6710 & 4288 & 5499 \\
\hline $\begin{array}{l}\text { C_Date } \\
18-28\end{array}$ & -5663 & -3944 & -5169 & -3965 & 7187 & 5983 & \\
\hline $\begin{array}{l}\text { C_Date } \\
18-36\end{array}$ & -6084 & -4684 & -5407 & -4522 & 7425 & 6540 & \\
\hline E8 & & & -5573 & -4698 & 7591 & 67167 & 153.5 \\
\hline $\begin{array}{l}\text { C_Date } \\
18-37\end{array}$ & -5764 & -4484 & -5714 & -4912 & 7732 & 6930 & \\
\hline $\begin{array}{l}\text { C_Date } \\
18-39\end{array}$ & -6564 & -5124 & -5971 & -5129 & 7989 & 7147 & \\
\hline E9 & & & -6183 & -5254 & 8201 & 7272 & 736.5 \\
\hline $\begin{array}{l}\text { C_Date } \\
18-40\end{array}$ & -6264 & -4944 & -6362 & -5392 & 8380 & 7410 & \\
\hline $\begin{array}{l}\text { Boundary } \\
\text { Base }\end{array}$ & & & -7316 & -5437 & 9334 & 7455 & \\
\hline
\end{tabular}




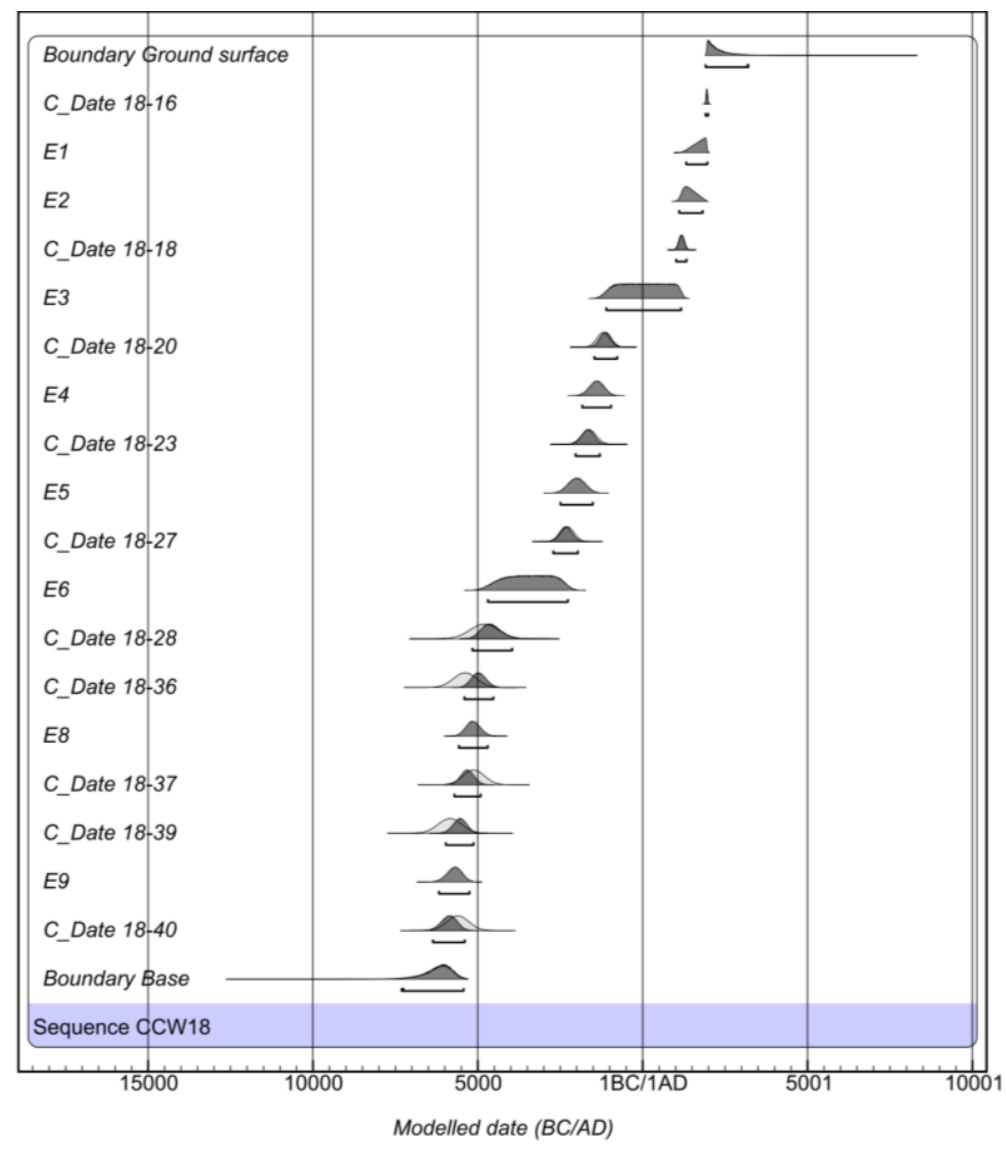

Figure 13. OxCal model showing sample and event probability density functions before and after Bayesian approach was used to reweight the probability density functions. 


\section{CHAPTER FIVE}

\section{CONCLUSIONS}

The CCW site provides the longest paleoseismic record constructed on the central section of the Garlock Fault compared to paleoseismic records of neighboring sites. Evidence for ten earthquake horizons were identified based on sedimentological responses to deformation and fault terminations at each horizon. Events in the upper tier have higher quality and correlation ratings than those in the lower tier, due to the more continuous, less bioturbated stratigraphy in the upper tier. The most recent event occurred between 115-696 BP and the average recurrence interval between events $1-8$ is $808-911$ years. The dates of prehistoric earthquakes at the CCW paleoseismic site do not perfectly match the event ages found at paleoseismic sites farther east and west along the central GF. The CCW site has evidence for only 3 earthquakes during the cluster of four earthquakes seen at EPP within the past $2 \mathrm{ka}$, and it records at least two faulting events (event 4 and 5) that occurred within the seismic hiatus between 2-5 ka at EPP. Thus, the results from CCW do not clearly support the same cluster and lull behavior that was observed at El Paso Peaks. However, they do still suggest a somewhat irregular recurrence interval for the Garlock Fault at CCW with some intervals as short as 200 years or less and others as long as 1500 years or more. This suggests that the central Garlock Fault may also be exhibiting cluster and lull behavior, but does not identify if the present day represents a lull. 


\section{APPENDIX A}

FIGURES SHOWING ALL TRENCH EXPOSURES COMBINED AND RELATIONSHIPS BETWEEN EXPOSURES 


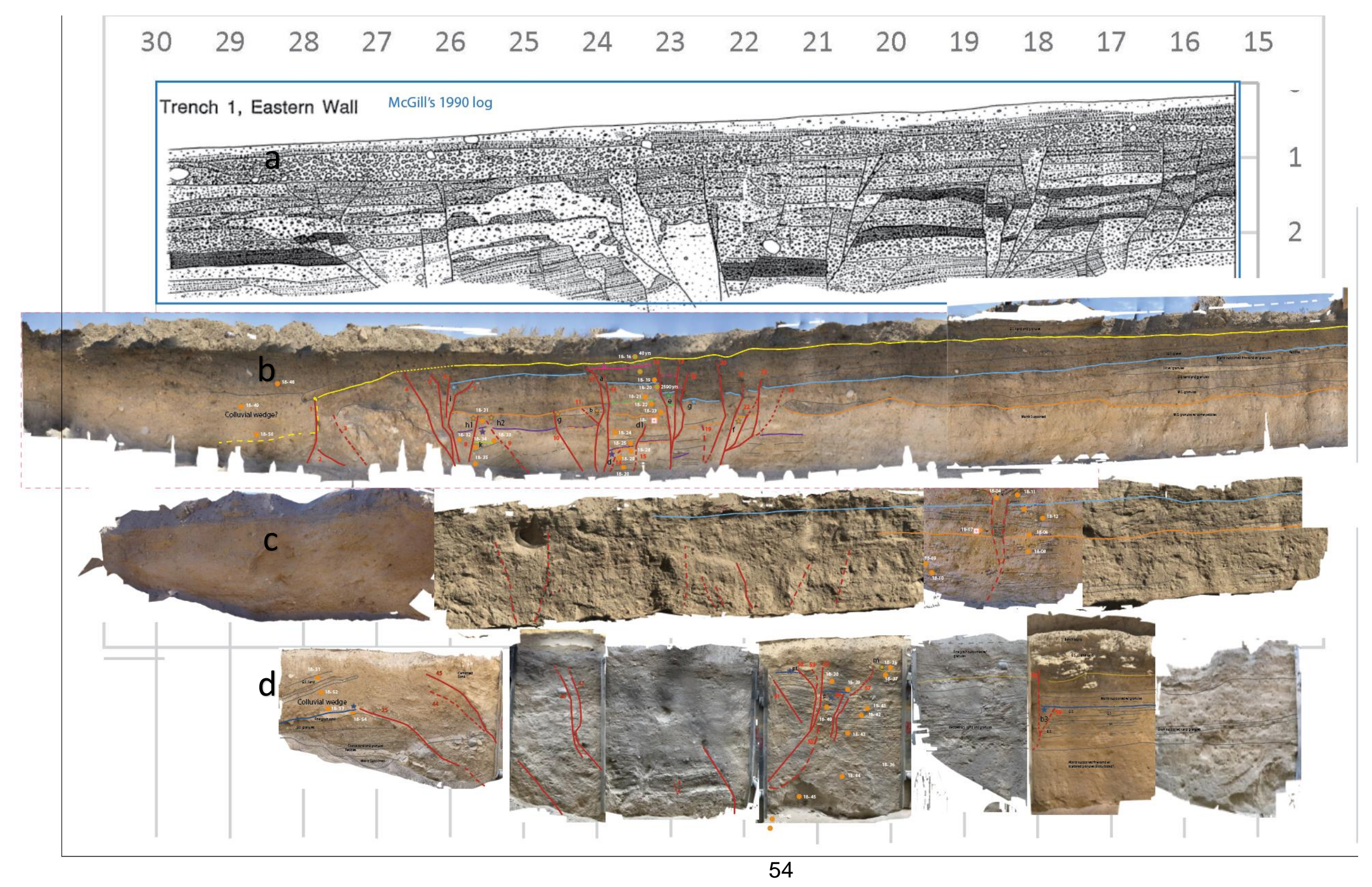


Figure A1: (a) Original trench log from McGill (1990). (b) Full mosaics of the east wall upper tier of phase 2. (c) Full mosaic of east wall phase 1, and (d) full mosaic of east wall deep slot (phase 2). Note: Each tier is plotted individually. The vertical distance between tiers is arbitrary and does not represent the true relative vertical positions of the tiers. Panels (b) and (c) are at approximately the same elevation. Panels (a) and (b) were directly above panel (d) and Panel (c) was $\sim 1.5 \mathrm{~m}$ farther east. See figure A3 for relative positions of the tiers. 


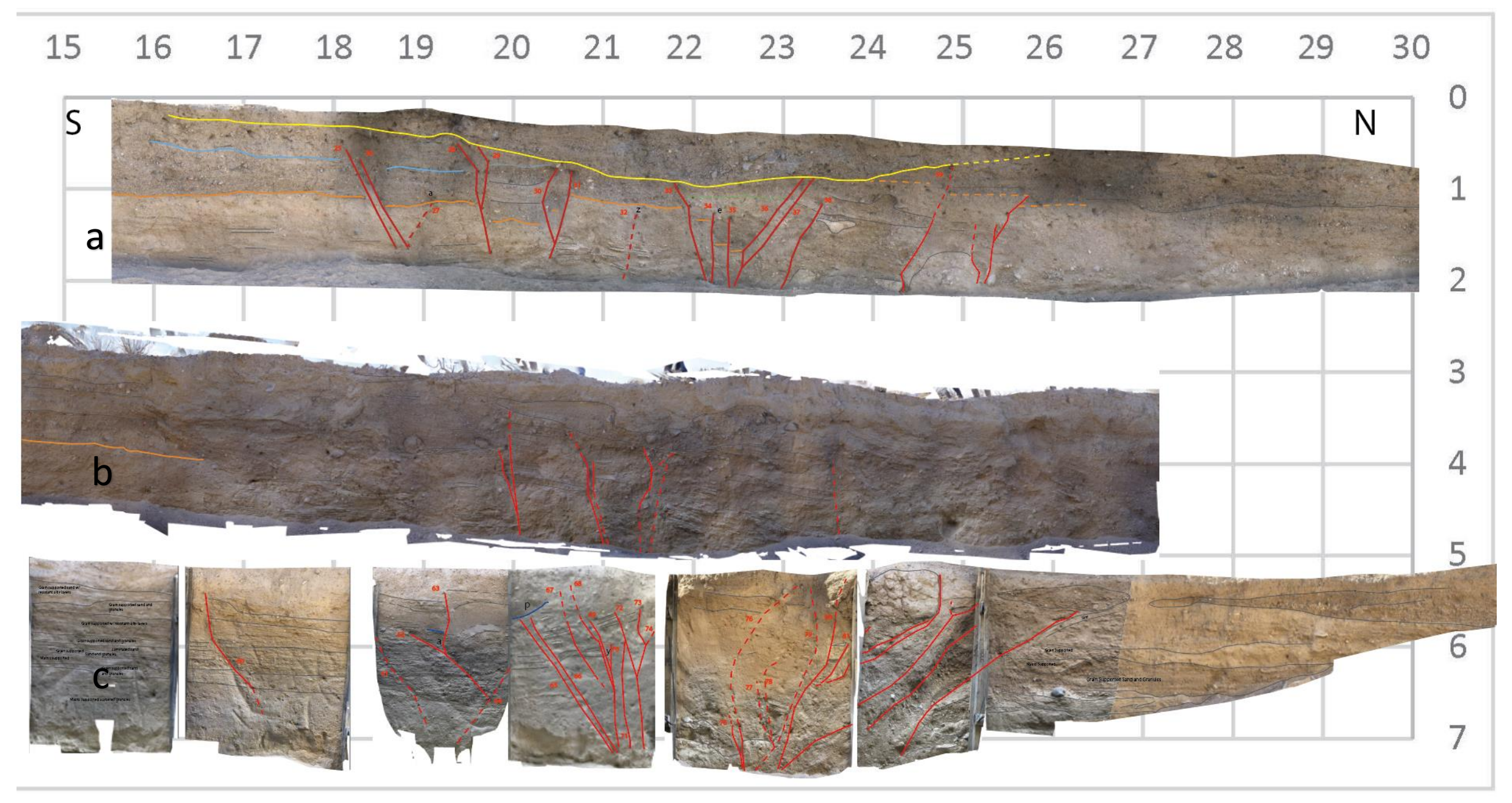


Figure A2: Mosaics of the fault zone in the west wall of the trench, showing upper tier of phase 2 (a), phase 1 (b), and deep slot of phase 2 (c). Note: Each tier is plotted individually. The vertical distance between tiers is arbitrary and does not represent the true relative vertical positions of the tiers. Panels (a) and (b) are at approximately the same elevation. Panel (b) was directly above panel (c) and Panel (a) was $\sim 1.5 \mathrm{~m}$ farther west. See figure A3 for relative positions of the tiers. 


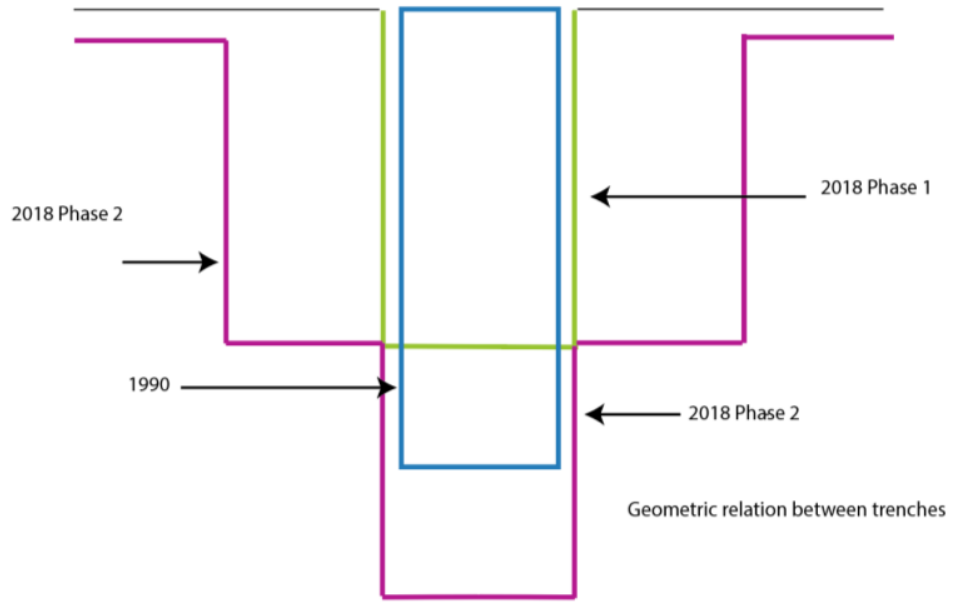

Figure A3: Schematic diagram (not to scale) across the width of the trench showing the relationships between each phase and tier of the CCW trench. Blue rectangle shows the original 1990 trench dimensions. The green shape indicates phase 1 of the 2018 trench, which was shallower in depth but the same width as the 1990 trench except for the walls being dug back a few centimeters. The pink shape indicates phase 2 of the 2018 trench, which deepened and widened phase 1 of the 2018 trench. 


\section{REFERENCES}

Aitken, M.J., 1998, An introduction to optical dating: The dating of Quaternary sediments by the use of photon-stimulated luminescence: Geological Magazine, v. 136, p. 83-108.

Associated Press, 2019, Unprecedented movement detected on Mojave Desert fault capable of magnitude 8.0-Caltech:

https://ktla.com/2019/10/17/unprecedented-movement-detected-onmojave-desert-fault-capable-of-magnitude-8-0-earthquake-caltech/ (accessed November 2019).

Benson, L., Currey, D., Dorn, R., Lajoie, K., Oviatt, C., Robinson, S., Smith, G., and Stine, S., 1990, Chronology of expansion and contraction of four Great Basin lake systems during the past 35,000 years: Palaeogeography, Palaeoclimatology, Palaeoecology, v. 78, p. 241-286.

Bilham, R., and Castillo, B., (in press), Triggered slip and afterslip in the July 2019 Ridgecrest earthquake sequence: Seismological Research Letters.

Burbank, D.W., and Whistler, D.P., 1987, Temporally constrained tectonic rotations derived from magnetostratigraphic data: Implication for the initiation of the Garlock Fault, California: Geology, v.15, p. 1172-1175.

Burke, D.B., 1979, Log of a trench in the Garlock Fault zone, Fremont Valley, California: United States Geological Survey Map MF-1028.

Burke, D.B., and Clark, M.M., 1978, Late Quaternary activity along the Garlock Fault at Koehn Lake, Fremont Valley, California: EOS Transactions of the American Geophysical Union, v. 59, p. 1126. 
Carr, M.D., Harris, A.G., Poole, F.G., and Fleck, R.J., 1992, Stratigraphy and structure of Paleozoic outer continental margin rocks in Pilot Knob, north central Mojave Desert, California: United States Geological Survey Bulletin 2015, p.1-33.

Castillo, B.A., 2019, Ages of prehistoric earthquakes on the Banning Strand of the San Andreas Fault, near North Palm Springs, California, [unpublished Master of Science Thesis]: California State University, San Bernardino, 84 p.

Clark, M.M., and Lajoie, K.R., 1974, Holocene behavior of the Garlock Fault: Geological Society of America Abstracts with Programs, v. 6, no. 7, p. 156.

Davis, G.A., and Burchfiel, B.C., 1973, Garlock Fault: an intracontinental transform structure, Southern California: Geological Society of America Bulletin, v. 84, p. 1407-1422.

Dawson, T.E., McGill, S.F., and Rockwell, T.K., 2003, Irregular recurrence of paleoearthquakes along the central Garlock fault near El Paso Peaks, California: Journal of Geophysical Research, v. 108, no. B7, p. 2356, doi:10.1029/2001JB001744.

Dolan, J.F., McAuliffe, L.J., Rhodes, E.J., McGill, S.F., and Zinke, R., 2016, Extreme multi-millenial slip rate variations on the Garlock fault, California: Strain super-cycles, potentially time-variable fault strength, and implications for system-level earthquake occurrence: Earth and Planetary Science Letters, v. 446, p. 123-136. 
Ganev, P.N., Dolan, J.F., McGill, S.F., and Frankel, K.L., 2012, Constancy of geologic slip rate along the central Garlock fault: implications for strain accumulation and release in Southern California: Geophysical Journal International, v. 190, p. 745-750.

Geotechnical Extreme Event Reconnaissance Association, 2019, Preliminary report on engineering and geological effects of the July 2019 Ridgecrest earthquake sequence, v. 1 :

http://www.geerassociation.org/administrator/components/com_geer_repo rts/geerfiles/GEER_Ridgecrest_report_ver1.pdf (accessed November 2019).

Hanks, T.C., Hileman, J. A., and Thatcher, W., 1975, Seismic moments of the larger earthquakes of the southern California region: Geological Society of America Bulletin, v. 86, p. 1131-1139.

Kemp, C.D., Hartleb, R., Lutz, A., Frost, E., and Lindvall, S., 2016, Paleoearthquake chronology from the Echo Playa Site on the central Garlock Fault, California: Seismological Research Letters, v. 87, p. 582.

Loomis, D.P., and Burbank, D.W., 1987, The stratigraphic evolution of the El Paso basin, southern California: Implications for the Miocene development of the Garlock fault and uplift of the Sierra Nevada: Geological Society of America Bulletin, v. 100, p. 12-28.

Madugo, C.M., Dolan, J.F., and Hartleb, R.D., 2012, New paleoearthquake ages from the western Garlock Fault: Implications for regional earthquake 
occurrence in Southern California: Bulletin of the Seismological Society of America, v. 102, p. 2282-2299. doi: https://doi.org/10.1785/0120110310.

McGill, S.F., and Sieh, K., 1991, Surficial offsets on the central and eastern Garlock Fault associated with prehistoric earthquakes: Journal of Geophysical Research, v. 96, p. 21,597-21,621.

McGill, S.H.F., 1992, Paleoseismology and neotectonics of the central Garlock fault, [Ph.D. dissertation]: California Institute of Technology, $235 \mathrm{p}$.

McGill, S.F., and Sieh, K.,1993, Holocene slip rate of the central Garlock Fault in southeastern Searles Valley, California: Journal of Geophysical Research, v.98, p. $14,217-14,231$.

McGill, S., and Rockwell, T., 1998, Ages of late Holocene earthquakes on the central Garlock fault near El Paso Peaks, California: Journal of Geophysical Research, v. 103, p. 7265-7279.

McGill, S.F., Wells, S.G., Fortner, S.K., Kuzma, H.A., and McGill, J.D., 2009, Slip rate of the western Garlock Fault, at Clark Wash, near Lone Tree Canyon, Mojave Desert, California: Geological Society of America Bulletin, v. 121, p. 536-554.

Monastero, F.C., Sabin, A.E., and Walker, J.D., 1997, Evidence for post-early Miocene initiation of movement on the Garlock fault from offset of the Cudahy Camp Formation east-central California: Geology, v. 25, p. 247250. 
Murray, A.S., and Wintle, A.G., 2000, Luminescence dating of quartz using an improved single-aliquot regenerative-dose protocol: Radiation Measurements, v. 32, p. 57-73.

Oskin, M., Perg, L., Shelef, E., Strane, M., Gurney, E., Singer, B., Zhang, X., 2008, Elevated shear zone loading rate during an earthquake cluster in eastern California: Geology, v.36, p.507-510.

Ramsey, C.B., 2009, Bayesian analysis of radiocarbon dates: Radiocarbon, v. 51, p. 337-360, doi: 10.1017/S0033822200033865.

Rittase, W.M., Kirby, E., McDonald, E., Walker, J.D., Gosse, J., Spencer, J.O.G., and Herrs, A.J., 2014, Temporal variations in Holocene slip rate along the central Garlock fault, Pilot Knob Valley, California: Lithosphere, v. 6, p. 4858.

Rhodes, J., 2015, Dating sediments using potassium feldspar single-grain IRSL: Initial methodological considerations: Quaternary International, v. 362, p. 14-22.

Ross, Z.E., Idini, B., Jia, Z., Stephenson, O.L., Zhong, M., Wang, X., Zhan, Z., Simons, M., Fielding, E.J., Yun, S., Hauksson, E., Moore, A.W., Liu, Z., and Jung, J., 2019, Hierarchical interlocked orthogonal faulting in the 2019 Ridgecrest earthquake sequence: Science, v. 366, p. 346-351.

Rubin, C.M., and Sieh, K., 1997, Long dormancy, low slip rate, and similar slipper-event for the Emerson Fault, eastern California shear zone: Journal of Geophysical Research, v. 102, p. 15319-15333. 
Scharer, K., Weldon, R. II, Biasi G., Streig A., and Fumal T., 2017, Groundrupturing earthquakes on the northern big bend of the San Andreas Fault, California, 800 A.D. to Present, Journal of Geophysical Research, v. 122, p.2193- 2218 doi:10.1002/2016JB013606.

Smith, G.I., 1962, Large lateral displacement on Garlock fault, as measured from offset dike swarm: American Association of Petroleum Geology Bulletin, v. 46 , p. $85-104$.

Smith, G.I., and Ketner, K.B., 1970, Lateral displacement on the Garlock fault, southeastern California, suggested by offset sections of similar metasedimentary rocks: United States Geologic Survey, Professional Paper 700-D, p. D1-D9.

Stein, R.S., Rollins, C., Sevilgen, V., and Hobbs, T., 2019, M 7.1 SoCal earthquake triggers aftershocks up to 100 mi away: What's next?: https://temblor.net/earthquake-insights/m-7-1-socal-earthquake-triggersaftershocks-up-to-100-mi-away-whats-next-9055/ (accessed November 2019).

Struiver, M., and Smith, G.I., 1979, Radiocarbon ages of stratigraphic units, in Smith, G.I., ed., Subsurface stratigraphy and geochemistry of Late Quaternary evaporates, Searles Lake, California: United States Geological Survey Professional Paper 1043, p. 1-130.

U.S. Geological Survey, 2019a, M 6.4-11 km SW of Searles Valley, CA: Earthquake hazards program: https://earthquake.usgs.gov/earthquakes/eventpage/ci38443183 
U.S. Geological Survey, 2019b, M 7.1 - 18km W of Searles Valley, CA:

Earthquake hazards program:

https://earthquake.usgs.gov/earthquakes/eventpage/ci38457511

U.S. Geological Survey, 2019c, Surface Ruptures from the July 4 and 5

Ridgecrest, CA Earthquakes: Earthquake hazards program:

https://www.usgs.gov/media/images/surface-ruptures-july-4-and-5-

ridgecrest-ca-earthquakes

Williams, P. L., McGill, S.F., Sieh, K.E., Allen, C.R., and Louie, J.N., 1988, Triggered slip along the San Andreas fault after the 8 July 1986 North Palm Springs earthquake: Bulletin of the Seismological Society of America, v. 78, p. 1112-1122. 